\title{
The Impact of Penalty and Subsidy Mechanisms On The Decisions of Governments, Businesses, and Consumers During COVID-19 --Tripartite Evolutionary Game Theory Analysis
}

\author{
Yuxun Zhou ( $D$ 641318192@qq.com ) \\ University of Southern Queensland \\ Rahman Mohammad Mafizur \\ University of Southern Queensland \\ Khanam Rasheda \\ University of Southern Queensland \\ Brad R. Taylor \\ University of Southern Queensland
}

\section{Research Article}

Keywords: Evolutionary game theory, Tripartite game theory, COVID-19, Pandemic control policy

Posted Date: November 17th, 2021

DOI: https://doi.org/10.21203/rs.3.rs-1012076/v1

License: (c) (i) This work is licensed under a Creative Commons Attribution 4.0 International License.

Read Full License 


\title{
The Impact of Penalty and Subsidy Mechanisms on the Decisions of Governments, Businesses, and Consumers during COVID-19 Tripartite Evolutionary Game Theory Analysis
}

\author{
Yuxun Zhou \\ (The first and corresponding \\ author) \\ Mohammad Mafizur \\ Rahman \\ (The second author) \\ 641318192@qq.com \\ Mafiz.Rahman@usq.edu.au \\ Rasheda Khanam \\ (The third author) \\ Rasheda.Khanam@usq.edu. \\ School of Business \\ University of Southern Queensland \\ Toowoomba, QLD 4350, AUSTRALIA
}

Abstract:

Purpose - Based on the fact that punishment and subsidy mechanisms affect the anti-epidemic incentives of major participants in a society, the issue of this paper is how the penalty and subsidy mechanisms affect the decisions of governments, businesses, and consumers during Corona Virus Disease 2019. The goal of this paper is to understand strategic selections from governments, enterprises, and consumers to maximize their respective utility during Corona Virus Disease 2019, and the impact of penalty and subsidy mechanism on the decisions of governments, businesses, and consumers.

Design/Methodology/approach - This paper proposes a tripartite evolutionary game theory, involving governments, businesses, and consumers, to firstly analyze the evolutionary stable strategies and to secondly analyze the impact of penalty and subsidy mechanism on their strategy selection during Corona Virus Disease 2019. Thirdly, this paper uses numerical analysis to simulate the strategy formation process of governments, enterprises, and consumers in Japan and India based on their different penalty and subsidy mechanism.

Findings - This paper suggests that there are four evolutionarily stable strategies corresponding to the actual antiepidemic situations of different countries in reality. We find that different subsidy and penalty mechanisms lead to different evolutionary stable strategies. If governments, enterprises, and consumers fighting the pandemic together, the government need to set a low subsidy mechanism and a high penalty mechanism.

Originality/value - There are some limitations in the literature, such as long term strategies, rational hypothesis, and convergence path analysis in higher dimensional evolutionary game theory. This paper fills the gap and extends the theory of COVID-19 management theory. Firstly, this paper has important practical significance. This paper finds out the longterm equilibrium strategies of governments, businesses, and consumers under Corona Virus Disease 2019, which can provide an important theoretical and decision-making basis for pandemic prevention and control. Secondly, our paper extends the analytical paradigm of the tripartite evolutionary game theory. We extend the analysis of the dynamic process from the initial point to the convergence point and make a theoretical contribution to the development of high-dimensional evolutionary game theory.

Key word: Evolutionary game theory; Tripartite game theory; COVID-19; Pandemic control policy

\section{Introduction}

\subsection{Background}


The ongoing coronavirus 2019 (COVID-19) pandemic has presented an unprecedented threat to the physical and economic health of every country on earth. Not all countries have responded equally, however. Among other factors, the extent to which government successfully implements public health policies aimed at controlling the pandemic determines the level of harm suffered. To successfully fight the pandemic, governments, businesses, and individual must work together. As prior work in game theory has shown (Hart \& Mas-Colell, 1997), cooperation cannot be guaranteed even with shared goals. To understand why some countries have seen greater success than others in controlling the pandemic we must consider the strategic situation in which government, businesses, and individuals interact with one another. Without broad cooperation, the impacts of COVID-19 are unlikely to be successfully mitigated even if the medical infrastructure of a country seems up to the task.

In some countries, governments, businesses, and consumers are working together to take proactive preventive action against COVID-19. Why have not all countries been able to do this? Although there are doubtless many contextual factors which influence this, in this paper we consider the broad incentives for cooperation using the tools of game theory.

\subsection{Research objects and questions}

We begin with the truistic assumption that participants (including government, businesses, and individuals) will choose to actively fight the pandemic when doing so maximizes their utility. If an actor sees the all-things-considered payoff from non-cooperation as higher than that of cooperation they will choose not to cooperate. We assume that general cooperation is the socially optimal outcome here, but this outcome cannot be guaranteed as it is only one of several possible equilibria resulting from the individual players pursuing their own objectives. This leads us to our first research question:

RQ1: Whether there is a strategy profile, which enables governments, businesses, and consumers to meet their respective utility maximization during COVID-19?

In investigating question 1 , it will become apparent that broad cooperation among government, business, and citizens to actively counter the pandemic is only one of several possible social outcomes. Assuming this is the socially optimal choice, the relevant question to ask is whether and how such an outcome can be achieved in an incentive-compatible manner. We divide the incentive structure into "internal" and "external" components. The internal incentive structure includes factors such as citizens' trust in government, preferences over health and personal autonomy, etc. Although these are not immutable, they are relatively stable in the short term and unlikely to be influenced by public policy interventions or institutional changes. The external incentive structure includes material incentives, including the inducements and penalties implemented by government. The external incentive structure is therefore more variable and may change quite rapidly during a pandemic in a way which could shift individual choices and social outcomes.

To consider how such changes in the external incentive structure can influence choices and outcomes we model the impact of penalty and subsidy mechanisms on strategy choice and equilibrium using tripartite game theory, first in general terms and then numerically using plausible assumptions about the relative values of key parameters in different countries. Thus, our second research question:

RQ2: Whether penalty and subsidy mechanisms influence the strategies of governments, businesses, and consumers during COVID-19 and how this impacts the resulting equilibria?

\subsection{Related work and their limitations}

There has been much economic research conducted on the topic of decision-making during the COVID-19 pandemic. This divides broadly into two forms: empirical analysis of the impact of pandemic control policies on behavior, and the use of game theory to theoretically model the choices of governments, businesses, and citizens.

Chen, et al. (2020) empirically studied the driving factors of citizens' satisfaction with government responses. They found that citizens are more concerned with the outcomes of COVID-19 control than the specific policies implemented by the government. They also found that citizens' satisfaction with the government's response varies greatly from country to country. They suggest that when implementing pandemic control policies governments try to strike a balance between public health concerns (saving lives) and economic impacts (saving jobs), with different governments making different trade-offs between these competing objectives. 
In studying the impact of policy decisions on mortality, Silva and Tsigaris (2020) found that policy delays (in e.g. travel restrictions and public advocacy campaigns) increased mortality. Chen et al. (2020) studied the impact of restrictive policies on COVID-19 in East Asia. They found that the incidence of COVID-19 decreased after the implementation of a restrictive policy intervention. They argue that citizens' responsibility, collectivism, and vigilance assisted East Asian countries in successfully controlling COVID-19.

Other studies have investigated the informational impact of the government response on pandemic control. In a preCOVID-19 context, Kim and Liu (2012) had studied how governments should respond to a pandemic. They considered that the best response would be transparency and accountability. Vallejo and Ong (2020) researched the Philippine government's response to the COVID-19 outbreak, demonstrating that transparency and good information delivery mechanisms are key to dealing with public events.

The above quantitative studies provide important evidence about the effectiveness of pandemic policies, but provide only limited insight about the strategic considerations which drive the choices of governments, businesses, and individuals. This is where game theory can add value, and a number of studies have analyzed various aspects of the pandemic using this approach.

Anupam et al. (2020) studied the influence of social distance on the development of COVID-19 using non-cooperative game theory. They used non-cooperative games to provide citizens with incentives to keep social distance in order to prevent the spread of COVID-19, finding a Nash equilibrium to show the sustainability of restrictive policies. This study provides important insights into the incentives of players in a static game, but did not consider the long-term dynamics or the possibility of behavior which is irrational or based on poor information. The latter point is particularly important in the context of COVID-19, since misinformation and conspiracy theories are rife in this context (Kouzy et al, 2020). Prominent claims spread on social media include the ideas that the virus is caused by $5 \mathrm{G}$ towers or that the vaccines contain microchips. There is also widespread misinformation on infection and fatality rates. Exposure to such misinformation has been shown to change beliefs and reduce preventive behaviors (Lee et al 2020).

Murat and Burhaneddin (2021) studied the phased effects of isolation using non-cooperative games. They divided the development of COVID-19 into three phases: the start, the spread, and the end. They used South Korea, Italy, and Turkey as examples to study the impact of quarantine on the development of the pandemic. The results show that isolation has an important impact on the scale of infection and the development of the pandemic. This study introduces some dynamic elements by using repeated games to verify the necessity of continuous isolation. There are two limitations here, however. First, as above, the authors use a straightforward rationality assumption and do not account for imperfect information. Secondly, it does not consider the strategic situation facing governments and the incentives they have to implement policies to combat the pandemic. This is an important determinant of effective pandemic control, and countries vary in this respect.

Social distancing requirements force businesses to limit the number of customers at any given time. Yael and Uri (2020) use game theory to study the relationship between queuing time and infection risk and the incentives facing businesses and consumers. They find that risk of infection is proportional to the number of customers. Although this paper provides useful knowledge on this particular part of pandemic control, the scope is much narrower than the present study.

Zhi, et al. (2020) studied the long-term decisions of government, businesses and consumers under COVID-19 using tripartite evolutionary game theory. They concluded that proper subsidies, punishment mechanisms and public incentives would lead to tripartite cooperation to fight the pandemic. This study uses methodology similar to our own, but has three limitations. First, the authors incorrectly used Lyapunov's stable analysis. The value of the determinant formed by the eigenvalues of the four points in their Table 4 should be greater than zero rather than less than zero. Therefore, all the following conclusions are based on faulty analysis. Secondly, like most tripartite evolutionary game theory articles, they do not analyze the dynamic process of the phase diagram, that is, the dynamic process from the initial point to the convergence point. This is very important in this context since it allows us to consider behavioral change. Thirdly, punishment and subsidy mechanism are modelled identically in all cases, whereas we know that these differ across countries. 
The game theoretic studies outlined above provide important insights into pandemic policy, but there are three common limitations. First, there has been no analysis of the penalty and subsidy decision made by government. Second, most analyses have been based on a rationality assumption without considering information problems. Third, there has been a lack of attention to the dynamics of decision making.

\subsection{Contributions and significance of this study}

This paper attempts to fill these research gaps by modelling the impact of penalty and subsidy mechanism on decisions made by the government, businesses, and consumers, which will provide an important theoretical basis for the development of national pandemic control policies. The paper also contributes to the theoretical development of highdimensional evolutionary game theory. We will analyze the dynamics from the initial point to the convergency point, and it extend the analysis of high-dimensional evolutionary game theory.

\subsection{Structure of this study}

The rest of this paper is structured as follows: We outline the assumptions and construction of the model in Section 2 . In section 3, we provide solutions and analysis for both the general case and for specific countries based on plausible assumptions about key parameters. conclusion and summary of implications are in section 4.

\section{Model Assumptions}

Basic Assumption: We define a tripartite game space $\Omega=\left\{N, \Lambda,\left\{S_{i}\right\},\left\{U_{i}(\cdot)\right\}\right\}_{i \in N}$, where $N=\{G, M, C\}(G$ represents the government, $M$ represents businesses and $C$ represents consumers) is the participant set and $\left\{A_{i}\right\}_{i \in N} \subset \Lambda$ represents the player's $i$ th action set $\left(A_{G}=\right.$ Implement, Non - implement $\}, A_{M}=A_{C}=$ Active prevention, Negative prevention $\left.\}\right)$. $S_{i}=\left\{s_{i}^{(1)}, s_{i}^{(2)}, \ldots, s_{i}^{(n)}\right\}_{i \in N}$ denotes the participant $i$ th strategy set, that is participant $i$ has $n$ strategies. Their hybrid strategy $\sigma_{i}$ is a probability distribution over $S_{i}=\left\{s_{i}^{(1)}, s_{i}^{(2)}, \ldots, s_{i}^{(n)}\right\}_{i \in N}$, namely, $\left.\sigma_{i}: S_{i} \rightarrow[0,1]\right)$. $\left\{U_{i}(\cdot)\right\}_{i \in N}$ represents the payoff of the participant $i$ (the choice of actions by all players determines an outcome $z \in Z$ of the game). Thus, $U_{i}: Z \rightarrow \mathbb{R}$.

In the context of COVID-19, we choose the government, businesses, and consumers as game players. The actions of the government are to implement strict restrictive policies and not to implement strict restrictive policies. There are the two options for both businesses and consumers to choose: active prevention and negative prevention. Table 1 shows the static payoff matrix of a tripartite game.

Table 1. Payoff matrix for the government, businesses, and consumers.

\begin{tabular}{|c|cccc|}
\hline \multirow{2}{*}{ Government } & \multicolumn{4}{|c|}{ Businesses $\times$ Consumer } \\
\cline { 2 - 5 } & $\begin{array}{c}\text { Active prevention, } \\
\text { Negative prevention }\end{array}$ & $\begin{array}{c}\text { Active prevention, } \\
\text { Active prevention }\end{array}$ & $\begin{array}{c}\text { Non-anti-epidemic, } \\
\text { Negative prevention }\end{array}$ & $\begin{array}{c}\text { Negative prevention, } \\
\text { Active prevention }\end{array}$ \\
\hline Implement & $a_{11}, a_{12}, a_{13}$ & $a_{14}, a_{15}, a_{16}$ & $a_{17}, a_{18}, a_{19}$ & $a_{110}, a_{111}, a_{112}$ \\
$\begin{array}{c}\text { Non- } \\
\text { implement }\end{array}$ & $a_{21}, a_{22}, a_{23}$ & $a_{24}, a_{25}, a_{26}$ & $a_{27}, a_{28}, a_{29}$ & $a_{210}, a_{211}, a_{212}$ \\
\hline
\end{tabular}

Note: $a_{11}=U_{1}\left(s_{1}^{I}, s_{2}^{C}, s_{3}^{N C}\right), a_{12}=U_{2}\left(s_{2}^{C}, s_{1}^{I}, s_{3}^{N C}\right), a_{13}=U_{3}\left(s_{3}^{N C}, s_{1}^{I}, s_{2}^{C}\right), a_{14}=U_{1}\left(s_{1}^{I}, s_{2}^{C}, s_{3}^{C}\right), a_{15}=U_{2}\left(s_{2}^{C}, s_{1}^{I}, s_{3}^{C}\right), a_{16}=U_{3}\left(s_{3}^{C}, s_{1}^{I}, s_{2}^{C}\right), a_{17}=U_{1}\left(s_{1}^{I}, s_{2}^{N C}, s_{3}^{N C}\right)$, $a_{18}=U_{2}\left(s_{2}^{N C}, s_{1}^{I}, s_{3}^{N C}\right), a_{19}=U_{3}\left(s_{3}^{N C}, s_{1}^{I}, s_{2}^{N C}\right), a_{110}=U_{1}\left(s_{1}^{I}, s_{2}^{N C}, s_{3}^{C}\right), a_{111}=U_{2}\left(s_{2}^{N C}, s_{1}^{I}, s_{3}^{C}\right), a_{112}=U_{3}\left(s_{3}^{C}, s_{1}^{I}, s_{2}^{N C}\right), a_{21}=U_{1}\left(s_{1}^{N I}, s_{2}^{C}, s_{3}^{N C}\right), a_{22}=U_{2}\left(s_{2}^{C}, s_{1}^{N I}, s_{3}^{N C}\right)$, $a_{23}=U_{3}\left(s_{3}^{N C}, s_{1}^{N I}, s_{2}^{C}\right), a_{24}=U_{1}\left(s_{1}^{N I}, s_{2}^{C}, s_{3}^{C}\right), a_{25}=U_{2}\left(s_{2}^{C}, s_{1}^{N I}, s_{3}^{C}\right), a_{26}=U_{3}\left(s_{3}^{C}, s_{1}^{N I}, s_{2}^{C}\right), a_{27}=U_{1}\left(s_{1}^{N I}, s_{2}^{N C}, s_{3}^{N C}\right), a_{28}=U_{2}\left(s_{2}^{N C}, s_{1}^{N I}, s_{3}^{N C}\right), a_{29}=U_{3}\left(s_{3}^{N C}, s_{1}^{N I}, s_{2}^{N C}\right)$, $a_{210}=U_{1}\left(s_{1}^{N I}, s_{2}^{N C}, s_{3}^{C}\right), a_{211}=U_{2}\left(s_{2}^{N C}, s_{1}^{N I}, s_{3}^{C}\right), a_{212}=U_{3}\left(s_{3}^{C}, s_{1}^{N I}, s_{2}^{N C}\right)$.

Assumption 1: The government has three broad objectives: 
1. Increasing the social welfare of citizens

2. Increasing re-election prospects by improving public opinion

3. Increasing government revenue net of spending in order to fund activities to pursue the above two objectives.

We assume, therefore, that the utility of the government consists of three parts: welfare utility, re-election utility, and financial utility. Anti-pandemic policies such as mask mandates, lockdowns, and vaccine subsidies have both benefits and costs in terms of these three objectives. Actively fighting the pandemic will increase social welfare by improving health outcomes but many policies (e.g. lockdowns, social distancing requirements) could also reduce economic activity and thus reduce social welfare. Given the extreme nature of the situation and the success countries have had when tackling the pandemic early, we assume that social welfare will be maximized with a strong policy response.

Depending on the preferences of citizens, active public health policy could either increase or decrease re-election prospects. Those citizens concerned with their health and worried about the pandemic will reward government by voting for them at the next election if the virus is successfully controlled (i.e. retrospective voting based on pandemic outcomes) and for enacting policies which are seen as proactive. Citizens who value freedom over health or are skeptical of the threat of the pandemic, on the other hand, will vote against incumbent government who impose strict policies. The relative proportion of these different types of voters in a population is therefore important. Finally, different policy choices will have different fiscal implications for government. Fines for noncompliance could bring in money, while subsidies, enforcement of policies, and research funding will all be costly.

We thus assume that government gains basic social welfare utility $u_{b} \in \mathbb{R}_{+}$if it imposes strict pandemic policy. To consider re-election utility, we distinguish two citizen types: "health-centred" (i.e. those who value pandemic control above other factors in the context of the COVID-19 pandemic and support strict policy imposed by government) and "freedom-centred" citizens (i.e. those who value other factors such as consumption and freedom above pandemic control and thus oppose strict policies). On this basis, if the businesses and the consumers are health-centred and choose to cooperate with pandemic control, the additional positive utility $\left\{R_{M}^{j}\right\}_{j=1}^{\infty} \subseteq \mathbb{R}_{+}$and $\left\{R_{C}^{a j}\right\}_{j=1}^{\infty} \subseteq \mathbb{R}_{+}$will be given to the government. If the businesses and consumers are freedom-centred and choose not to cooperate, the additional utility to the government are $\left\{R_{C}^{r j}\right\}_{j=1}^{\infty} \subseteq \mathbb{R}_{-}$and $\left\{R_{C}^{r j}\right\}_{j=1}^{\infty} \subseteq \mathbb{R}_{-}$, respectively.

When the government chooses not to impose strict restrictions, it gains a basic utility of 0 and if consumers and businesses choose active prevention, they give the government a negative additional utility $-\left\{R_{C}^{a j}\right\}_{j=1}^{\infty} \subseteq \mathbb{R}_{-}$. Of course, the government also will receive fines $\left\{c_{p}^{i}\right\}_{i \in N \backslash\{G\}} \subseteq \mathbb{R}_{+}$from businesses and consumers if they do not cooperate when the government imposes restrictions. Similarly, we assume that if the government chooses to impose strict restrictions, it will pay a basic cost $c_{0} \in \mathbb{R}_{+}$. If the businesses and the consumer choose active prevention, the additional cost to the government is 0 ; If businesses and consumers choose non-anti-epidemic, the additional cost to the government is $\left\{c_{i}^{G}\right\}_{i \in N \backslash\{G\}} \in \mathbb{R}_{+}$. If the government imposes strict restrictions, the government will subsidize the businesses or consumer, namely, the cost of the subsidy $\left\{S_{G}^{i}\right\}_{i \in N \backslash\{G\}} \subseteq \mathbb{R}_{+}$. Therefore, $\forall R_{M} \in\left\{R_{M}^{j}\right\}_{j=1}^{\infty}, \forall R_{C}^{a} \in\left\{R_{C}^{a j}\right\}_{j=1}^{\infty}$ and $R_{C}^{r} \in\left\{R_{C}^{r j}\right\}_{j=1}^{\infty}$, we have: $a_{14}=u_{b}+R_{M}+R_{C}^{a}-c_{0}-S_{G}^{M}-S_{G}^{C}, a_{110}=u_{b}+R_{c}^{a}+c_{p}^{M}-S_{G}^{C}-c_{0}-c_{M}^{G}, a_{27}=0, a_{21}=-R_{M}, a_{24}=$ $-R_{M}-R_{C}^{a}, a_{210}=-R_{C}^{a}, a_{11}=u_{b}+R_{M}+c_{p}^{C}-S_{G}^{M}-c_{0}-c_{c}^{G}-R_{C}^{r}, a_{17}=c_{p}^{C}+c_{p}^{M}+u_{b}-c_{0}-R_{M}-R_{C}^{r}$.

We assume that $x \in[0,1]$ probability of the government chooses to implement strict restrictive policies and $1-x$ probability of the government participants chooses to not implement strict restrictive policies.

Assumption 2: The total utility of consumers is mainly composed of five parts:

1. The health utility of consumers.

2. Other utilities for consumers including consumption, entertainment, freedom, etc. 
3. The wages of consumers (monetary utility).

4. Subsidies from the government as mentioned above in the government assumptions.

5. Subsidies from businesses. In some countries, companies offer freely health subsidies to consumers, including free masks and disinfectant.

We assume that for all consumers, their utility consists of two parts: health utility $u_{h} \in \mathbb{R}_{+}$and other utility $u_{o} \in \mathbb{R}_{+}$. For health-centred consumers, their health benefits outweigh other benefits. For freedom-centred consumers, their other utility is greater than the health utility. Therefore, regardless of the strict restrictive measures adopted by the government, freedom-centred consumers gain other utility $u_{o} \in \mathbb{R}_{+}$, and health-centred consumers gain health utility $u_{h} \in \mathbb{R}_{+}$. Consumers will pay three kinds of costs: medical costs $c_{m}^{C} \in \mathbb{R}_{+}$, other consumption costs $c_{o}^{C} \in \mathbb{R}_{+}$and punishment cost $c_{p}^{C} \in\left\{c_{p}^{i}\right\}_{i \in N \backslash\{G\}} \subseteq \mathbb{R}_{+}$. The income structure of consumers is a basic wage $W_{0} \in \mathbb{R}_{+}$plus performance wage $W \in \mathbb{R}_{+}$. If the businesses choose active anti-epidemic, the consumers receive only a basic wage. If the businesses choose giving up active prevention, while the consumers choose active anti-epidemic, then the consumers' total wage is 0 . If both the businesses and consumers choose giving up active prevention, the consumers can get all the wages. If businesses choose active prevention, or the government choose to restrict, consumers will receive subsidies $S^{M} \in \mathbb{R}_{+}$and $S_{G}^{C} \in$ $\left\{S_{G}^{i}\right\}_{i \in N \backslash\{G\}} \subseteq \mathbb{R}_{+}$. Thus, we have: $a_{26}=u_{h}+W_{0}+S^{M}-c_{o}^{C}, a_{212}=u_{h}-c_{o}^{C}, a_{16}=u_{h}+W_{0}+S^{M}+S_{G}^{C}-c_{o}^{C}$, $a_{112}=u_{h}+S_{G}^{C}-c_{o}^{C}, a_{23}=a_{29}=u_{o}+W_{0}+W-c_{m}^{C}-c_{o}^{C}, a_{19}=a_{13}=u_{o}+W_{0}+W-c_{m}^{C}-c_{o}^{C}-c_{p}^{C}$.

We assume that $y \in[0,1]$ probability of consumers choosing active prevention with the government and $1-y$ probability of the consumers choosing non-anti-epidemic.

Assumption 3: The utility of businesses mainly consists of two parts:

1. The profit of businesses. It also can be divided into two parts: basic profit and performance profit. Basic profit refers to the profit that an enterprise can get regardless of whether a pandemic occurs. Profit for performance refers to the extra profit an enterprise can get (During COVID-19, employees working at home have reduced the enterprise output. We take the sales staff as an example. Due to the government's restrictive policies, the sales staff cannot sell products outside, which results the profits decreasing. This is performance profits).

2. The government subsidies during COVID-19 as we have mentioned before. The main costs to the businesses are as follows: consumer wages, enterprise-to-consumer subsidies, and penalties paid by the businesses for breaking restrictive policies.

If the government chooses not to fight the epidemic, on the one hand, businesses will not receive the government subsidies. On the other hand, they will not have to pay penalty costs. If consumers are freedom-centred, businesses will not pay the enterprise-to-consumer subsidies. This is because the enterprise gives employees health subsidies to guarantee health-centried consumers' right, such as sending masks, disinfectant for free.

Therefore, the net utility of businesses is the difference between their total utility and total costs. Whether businesses should take active anti-epidemic measures depends on which option maximizes their net utility.

Thus, the profit of businesses consists of two parts: basic profit $\pi_{0} \in \mathbb{R}$ and performance profit $\pi \in \mathbb{R}$. If the government imposes strict restrictions and businesses choose to actively fight the pandemic, they will receive subsidies $S_{G}^{M} \in$ $\left\{S_{G}^{i}\right\}_{i \in N \backslash\{G\}} \subseteq \mathbb{R}_{+}$from the government. The cost of the businesses mainly consists of the base wage $W_{0} \in \mathbb{R}_{+}$and performance wage $W \in \mathbb{R}_{+}$of the consumers. If the government imposes strict restrictions while the businesses does not cooperate, the businesses will pay penalty costs $c_{p}^{M} \in\left\{c_{p}^{i}\right\}_{i \in N \backslash\{G\}} \subseteq \mathbb{R}_{+}$. Thus, we have: $a_{28}=\pi_{0}+\pi-W_{0}-W$, $a_{211}=\pi_{0}-W_{0}, a_{18}=\pi_{0}+\pi+S_{G}^{M}-W_{0}-W-c_{p}^{M}, a_{111}=\pi_{0}+S_{G}^{M}-W_{0}-c_{p}^{M}, a_{15}=\pi_{0}+S_{G}^{M}-W_{0}-S^{M}$, $a_{12}=\pi_{0}+\pi+S_{G}^{M}-W_{0}-W, a_{25}=\pi_{0}-W_{0}-S^{M}, a_{22}=\pi_{0}+\pi-W_{0}-W$. 
We assume that $z \in[0,1]$ probability of businesses choosing active prevention with the government and $1-z$ probability of the businesses choosing not to cooperate. Table 2 shows the parameter description.

Table 2. The description of the parameters

\begin{tabular}{|c|c|}
\hline Parameters & Description \\
\hline$u_{b} \in \mathbb{R}_{+}$ & Basic utility of the government \\
\hline$\left\{R_{M}^{j}\right\}_{j=1}^{\infty} \subseteq \mathbb{R}_{+}$ & $\begin{array}{l}\text { Additional utility gained for the government from } \\
\text { businesses }\end{array}$ \\
\hline$\left\{R_{C}^{r j}\right\}_{j=1}^{\infty} \subseteq \mathbb{R}_{-}$ & $\begin{array}{l}\text { Additional utility gained for the government from freedom- } \\
\text { centred consumers }\end{array}$ \\
\hline$\left\{R_{C}^{a j}\right\}_{j=1}^{\infty} \subseteq \mathbb{R}_{+}$ & $\begin{array}{l}\text { Additional utility gained for the government from health- } \\
\text { centred consumers }\end{array}$ \\
\hline$c_{0} \in \mathbb{R}_{+}$ & $\begin{array}{c}\text { Basic cost of the government if implementing strict } \\
\text { restrictions }\end{array}$ \\
\hline$\left\{c_{i}^{G}\right\}_{i \in N \backslash\{G\}} \in \mathbb{R}_{+}$ & $\begin{array}{l}\text { Additional cost for the government if businesses and } \\
\text { consumers do not cooperate }\end{array}$ \\
\hline$\left\{S_{G}^{i}\right\}_{i \in N \backslash\{G\}} \subseteq \mathbb{R}_{+}$ & $\begin{array}{c}\text { Subsidy for businesses and consumers from the government } \\
\text { if implementing strict restrictions }\end{array}$ \\
\hline$u_{h} \in \mathbb{R}_{+}$ & Health utility of consumers \\
\hline$u_{o} \in \mathbb{R}_{+}$ & Other utility of consumers \\
\hline$c_{m}^{C} \in \mathbb{R}_{+}$ & Medical cost of consumers \\
\hline$c_{o}^{C} \in \mathbb{R}_{+}$ & Other consumption cost of consumers \\
\hline$W_{0} \in \mathbb{R}_{+}$ & Basic wage of consumers \\
\hline$W \in \mathbb{R}_{+}$ & Performance wage of consumers \\
\hline$\left\{c_{p}^{i}\right\}_{i \in N \backslash\{G\}} \subseteq \mathbb{R}_{+}$ & $\begin{array}{l}\text { Punishment cost for consumers and businesses if the } \\
\text { government implements strict restrictions while consumers } \\
\text { and businesses do not cooperate }\end{array}$ \\
\hline$S^{M} \in \mathbb{R}_{+}$ & $\begin{array}{c}\text { Health subsidy gained for consumers from businesses if } \\
\text { both businesses and consumers have active prevention } \\
\text { actions }\end{array}$ \\
\hline$\pi_{0} \in \mathbb{R}_{+}$ & Basic profit of businesses \\
\hline$\pi \in \mathbb{R}_{+}$ & Additional profit of businesses \\
\hline
\end{tabular}

\section{Model Analysis and Implications}

\subsection{Evolutionary stable strategy analysis}

The average payoff when the government chooses to implement strict restrictive policies is given by $\pi_{1}^{I}$. When government does not impose strict policies, the average payoff is given by $\pi_{1}^{N I}$. The total average payoff to government is $\bar{\pi}_{1}$. 


$$
\begin{aligned}
& \pi_{1}^{I}=y(1-z) U_{1}\left(s_{1}^{I}, s_{2}^{C}, s_{3}^{N C}\right)+y z U_{1}\left(s_{1}^{I}, s_{2}^{C}, s_{3}^{C}\right)+(1-y)(1-z) U_{1}\left(s_{1}^{I}, s_{2}^{N C}, s_{3}^{N C}\right)+(1-y) z U_{1}\left(s_{1}^{I}, s_{2}^{N C}, s_{3}^{C}\right) \\
& \begin{aligned}
& \pi_{1}^{N I}=y(1-z) U_{1}\left(s_{1}^{N I}, s_{2}^{C}, s_{3}^{N C}\right)+y z U_{1}\left(s_{1}^{N I}, s_{2}^{C}, s_{3}^{C}\right)+(1-y)(1-z) U_{1}\left(s_{1}^{N I}, s_{2}^{N C}, s_{3}^{N C}\right)+(1-y) z U_{1}\left(s_{1}^{N I}, s_{2}^{N C}, s_{3}^{C}\right) \\
& \bar{\pi}_{1}=x \pi_{1}^{I}+(1-x) \pi_{1}^{N I} \\
& \quad=x\left[y(1-z) U_{1}\left(s_{1}^{I}, s_{2}^{C}, s_{3}^{N C}\right)+y z U_{1}\left(s_{1}^{I}, s_{2}^{C}, s_{3}^{C}\right)+(1-y)(1-z) U_{1}\left(s_{1}^{I}, s_{2}^{N C}, s_{3}^{N C}\right)\right. \\
&\left.+(1-y) z U_{1}\left(s_{1}^{I}, s_{2}^{N C}, s_{3}^{C}\right)\right] \\
&+(1-x)\left[y(1-z) U_{1}\left(s_{1}^{N I}, s_{2}^{C}, s_{3}^{N C}\right)+y z U_{1}\left(s_{1}^{N I}, s_{2}^{C}, s_{3}^{C}\right)+(1-y)(1-z) U_{1}\left(s_{1}^{N I}, s_{2}^{N C}, s_{3}^{N C}\right)\right. \\
&\left.+(1-y) z U_{1}\left(s_{1}^{N I}, s_{2}^{N C}, s_{3}^{C}\right)\right]
\end{aligned}
\end{aligned}
$$

$\frac{d x}{d t}=x\left(\pi_{1}^{I}-\bar{\pi}_{1}\right)$

$$
\begin{aligned}
& =x(1-x)\left[y(1-z)\left(U_{1}\left(s_{1}^{I}, s_{2}^{C}, s_{3}^{N C}\right)-U_{1}\left(s_{1}^{N I}, s_{2}^{C}, s_{3}^{N C}\right)\right)+y z\left(U_{1}\left(s_{1}^{I}, s_{2}^{C}, s_{3}^{C}\right)-U_{1}\left(s_{1}^{N I}, s_{2}^{C}, s_{3}^{C}\right)\right)\right. \\
& +(1-y)(1-z)\left(U_{1}\left(s_{1}^{I}, s_{2}^{N C}, s_{3}^{N C}\right)-U_{1}\left(s_{1}^{N I}, s_{2}^{N C}, s_{3}^{N C}\right)\right) \\
& \left.+(1-y) z\left(U_{1}\left(s_{1}^{I}, s_{2}^{N C}, s_{3}^{C}\right)-U_{1}\left(s_{1}^{N I}, s_{2}^{N C}, s_{3}^{C}\right)\right)\right]
\end{aligned}
$$

Let $F_{1}(x, y, z)=\frac{d x}{d t}$. We consider 2 situations of the dynamic progress of $x$. Situation 1: When $y=$ $\frac{a_{27}-a_{17}-z\left(a_{110}-a_{210}-a_{17}+a_{27}\right)}{+a_{27}+z\left(a_{17}-a_{27}+a_{14}-a_{24}-a_{11}+a_{21}-a_{110}+a_{210}\right)}, F_{1}(x, y, z) \equiv 0$. Situation 1 means $\forall(x, y, z) \in\left\{\Delta S_{i}\right\}_{i \in N}$ is an $a_{11}-a_{21}-a_{17}+a_{27}+z\left(a_{17}-a_{27}+a_{14}-a_{24}-a_{11}+a_{21}-a_{110}+a_{210}\right)$
evolutionary stable point, that is, whether the government chooses to enforce strict restrictions or not, the government's strategy will not change over time. Situation 2: When $y \neq \frac{a_{27}-a_{17}-z\left(a_{110}-a_{210}-a_{17}+a_{27}\right)}{a_{11}-a_{21}-a_{17}+a_{27}+z\left(a_{17}-a_{27}+a_{14}-a_{24}-a_{11}+a_{21}-a_{110}+a_{210}\right)}$, let $F_{1}(x, y, z)=0$, we can have $x=0$ or $x=1$. To further analyze the evolutionary stable strategy, we go further with $F_{1}(x, y, z)$ as follows:

$$
\begin{aligned}
\frac{\partial F_{1}(x, y, z)}{\partial x}=[ & y(1-z)\left(U_{1}\left(s_{1}^{I}, s_{2}^{C}, s_{3}^{N C}\right)-U_{1}\left(s_{1}^{N I}, s_{2}^{C}, s_{3}^{N C}\right)\right)+y z\left(U_{1}\left(s_{1}^{I}, s_{2}^{C}, s_{3}^{C}\right)-U_{1}\left(s_{1}^{N I}, s_{2}^{C}, s_{3}^{C}\right)\right) \\
& +(1-y)(1-z)\left(U_{1}\left(s_{1}^{I}, s_{2}^{N C}, s_{3}^{N C}\right)-U_{1}\left(s_{1}^{N I}, s_{2}^{N C}, s_{3}^{N C}\right)\right) \\
& \left.+(1-y) z\left(U_{1}\left(s_{1}^{I}, s_{2}^{N C}, s_{3}^{C}\right)-U_{1}\left(s_{1}^{N I}, s_{2}^{N C}, s_{3}^{C}\right)\right)\right](1-2 x)
\end{aligned}
$$

When $y<\frac{a_{27}-a_{17}-z\left(a_{110}-a_{210}-a_{17}+a_{27}\right)}{a_{11}-a_{21}-a_{17}+a_{27}+z\left(a_{17}-a_{27}+a_{14}-a_{24}-a_{11}+a_{21}-a_{110}+a_{210}\right)},\left.\frac{\partial F_{1}(x, y, z)}{\partial x}\right|_{x=0}<0,\left.\frac{\partial F_{1}(x, y, z)}{\partial x}\right|_{x=1}>0$, thus, $x=0$ is an evolutionary stable point, namely, the government will ultimately choose not to impose strict restrictions.

When $y>\frac{a_{27}-a_{17}-z\left(a_{110}-a_{210}-a_{17}+a_{27}\right)}{a_{11}-a_{21}-a_{17}+a_{27}+z\left(a_{17}-a_{27}+a_{14}-a_{24}-a_{11}+a_{21}-a_{110}+a_{210}\right)},\left.\frac{\partial F_{1}(x, y, z)}{\partial x}\right|_{x=0}>0,\left.\frac{\partial F_{1}(x, y, z)}{\partial x}\right|_{x=1}<0$, thus, $x=1$ is an evolutionary stable point, namely, the government will ultimately choose to impose strict restrictions. We analyze $y$ in detail in section 4.

When the businesses choose fight the pandemic with the government, the utility $\pi_{2}^{C}$ denotes the average payoff, $\pi_{2}^{N C}$ denotes the average payoff when the businesses chooses not to fight the pandemic with the government and $\bar{\pi}_{2}$ denotes the total average payoff of the businesses.

$$
\begin{aligned}
& \pi_{2}^{C}=x(1-z) U_{2}\left(s_{2}^{C}, s_{1}^{I}, s_{3}^{N C}\right)+x z U_{2}\left(s_{2}^{C}, s_{1}^{I}, s_{3}^{C}\right)+(1-x)(1-z) U_{2}\left(s_{2}^{C}, s_{1}^{N I}, s_{3}^{N C}\right)+(1-x) z U_{2}\left(s_{2}^{C}, s_{1}^{N I}, s_{3}^{C}\right) \\
& \pi_{2}^{N C}=x(1-z) U_{2}\left(s_{2}^{N C}, s_{1}^{I}, s_{3}^{N C}\right)+x z U_{2}\left(s_{2}^{N C}, s_{1}^{I}, s_{3}^{C}\right)+(1-x)(1-z) U_{2}\left(s_{2}^{N C}, s_{1}^{N I}, s_{3}^{N C}\right)+(1-x) z U_{2}\left(s_{2}^{N C}, s_{1}^{N I}, s_{3}^{C}\right)
\end{aligned}
$$




$$
\begin{aligned}
\bar{\pi}_{2}=y \pi_{2}^{C}+(1 & -y) \pi_{2}^{N C} \\
& =y x(1-z) U_{2}\left(s_{2}^{C}, s_{1}^{I}, s_{3}^{N C}\right)+y x z U_{2}\left(s_{2}^{C}, s_{1}^{I}, s_{3}^{C}\right)+y(1-x)(1-z) U_{2}\left(s_{2}^{C}, s_{1}^{N I}, s_{3}^{N C}\right) \\
& +(1-x) z y U_{2}\left(s_{2}^{C}, s_{1}^{N I}, s_{3}^{C}\right)+(1-y) x(1-z) U_{2}\left(s_{2}^{N C}, s_{1}^{I}, s_{3}^{N C}\right)+(1-y) x z U_{2}\left(s_{2}^{N C}, s_{1}^{I}, s_{3}^{C}\right) \\
& +(1-y)(1-x)(1-z) U_{2}\left(s_{2}^{N C}, s_{1}^{N I}, s_{3}^{N C}\right)+(1-y)(1-x) z U_{2}\left(s_{2}^{N C}, s_{1}^{N I}, s_{3}^{C}\right)
\end{aligned}
$$

$\frac{d y}{d t}=y\left(\pi_{2}^{C}-\bar{\pi}_{2}\right)$

$$
\begin{aligned}
& =y(1-y)\left[x(1-z)\left(U_{2}\left(s_{2}^{C}, s_{1}^{I}, s_{3}^{N C}\right)-U_{2}\left(s_{2}^{N C}, s_{1}^{I}, s_{3}^{N C}\right)\right)+x z\left(U_{2}\left(s_{2}^{C}, s_{1}^{I}, s_{3}^{C}\right)-U_{2}\left(s_{2}^{N C}, s_{1}^{I}, s_{3}^{C}\right)\right)\right. \\
& +(1-x)(1-z)\left(U_{2}\left(s_{2}^{C}, s_{1}^{N I}, s_{3}^{N C}\right)-U_{2}\left(s_{2}^{N C}, s_{1}^{N I}, s_{3}^{N C}\right)\right) \\
& \left.+(1-x) z\left(U_{2}\left(s_{2}^{C}, s_{1}^{N I}, s_{3}^{C}\right)-U_{2}\left(s_{2}^{N C}, s_{1}^{N I}, s_{3}^{C}\right)\right)\right]
\end{aligned}
$$

Let $F_{2}(x, y, z)=\frac{d y}{d t}$, we discuss 2 situations of the dynamic progress of $y$. Situation 1 : When $z=$ $\frac{a_{28}-a_{25}-x\left(a_{12}-a_{18}-a_{22}+a_{28}\right)}{x\left(a_{15}-a_{111}+a_{22}-a_{28}-a_{25}+a_{211}\right)+a_{25}-a_{211}-a_{12}+a_{18}-a_{22}+a_{28}}, F_{2}(x, y, z) \equiv 0$. Situation 1 means $\forall(x, y, z) \in\left\{\Delta S_{i}\right\}_{i \in N}$ is an evolutionary stable point, that is, whether the government / consumers choose to enforce strict restrictions / cooperate or not, the businesses' strategy will not change over time. Situation 2: When $z \neq$

$$
a_{28}-a_{25}-x\left(a_{12}-a_{18}-a_{22}+a_{28}\right)
$$

$\overline{x\left(a_{15}-a_{111}+a_{22}-a_{28}-a_{25}+a_{211}\right)+a_{25}-a_{211}-a_{12}+a_{18}-a_{22}+a_{28}}$, let $F_{2}(x, y, z)=0$, we can have $y=0$ or $y=1$. To further analyze the evolutionary stability strategy, we go further with $F_{2}(y)$ as follows:

$$
\begin{aligned}
\frac{\partial F_{2}(x, y, z)}{\partial y}=[ & x(1-z)\left(U_{2}\left(s_{2}^{C}, s_{1}^{I}, s_{3}^{N C}\right)-U_{2}\left(s_{2}^{N C}, s_{1}^{I}, s_{3}^{N C}\right)\right)+x z\left(U_{2}\left(s_{2}^{C}, s_{1}^{I}, s_{3}^{C}\right)-U_{2}\left(s_{2}^{N C}, s_{1}^{I}, s_{3}^{C}\right)\right) \\
& +(1-x)(1-z)\left(U_{2}\left(s_{2}^{C}, s_{1}^{N I}, s_{3}^{N C}\right)-U_{2}\left(s_{2}^{N C}, s_{1}^{N I}, s_{3}^{N C}\right)\right) \\
& \left.+(1-x) z\left(U_{2}\left(s_{2}^{C}, s_{1}^{N I}, s_{3}^{C}\right)-U_{2}\left(s_{2}^{N C}, s_{1}^{N I}, s_{3}^{C}\right)\right)\right](1-2 y)
\end{aligned}
$$

When $z<\frac{a_{28}-a_{25}-x\left(a_{12}-a_{18}-a_{22}+a_{28}\right)}{x\left(a_{15}-a_{111}+a_{22}-a_{28}-a_{25}+a_{211}\right)+a_{25}-a_{211}-a_{12}+a_{18}-a_{22}+a_{28}},\left.\frac{\partial F_{2}(x, y, z)}{\partial y}\right|_{y=0}<0,\left.\frac{\partial F_{2}(x, y, z)}{\partial y}\right|_{y=1}>0$, thus, $y=0$ is an evolutionary stable point, namely, the government will ultimately choose not to impose strict restrictions.

When $z>\frac{a_{28}-a_{25}-x\left(a_{12}-a_{18}-a_{22}+a_{28}\right)}{x\left(a_{15}-a_{111}+a_{22}-a_{28}-a_{25}+a_{211}\right)+a_{25}-a_{211}-a_{12}+a_{18}-a_{22}+a_{28}},\left.\frac{\partial F_{2}(x, y, z)}{\partial y}\right|_{y=0}>0,\left.\frac{\partial F_{2}(x, y, z)}{\partial y}\right|_{y=1}<0$, thus, $y=1$ is an evolutionary stable point, namely, the government will ultimately choose to impose strict restrictions. We will analyze $y$ in detail in section 4.

When the consumers choose active prevention with the government, the utility $\pi_{3}^{C}$ denotes the average payoff, $\pi_{3}^{N C}$ denotes the average payoff when the consumers choose not to cooperate with the government and $\bar{\pi}_{3}$ denotes the total average payoff of the consumers.

$$
\begin{aligned}
& \pi_{3}^{C}=x y U_{3}\left(s_{3}^{C}, s_{1}^{I}, s_{2}^{C}\right)+x(1-y) U_{3}\left(s_{3}^{C}, s_{1}^{I}, s_{2}^{N C}\right)+(1-x) y U_{3}\left(s_{3}^{C}, s_{1}^{N I}, s_{2}^{C}\right)+(1-x)(1-y) U_{3}\left(s_{3}^{C}, s_{1}^{N I}, s_{2}^{N C}\right) \\
& \begin{aligned}
\pi_{3}^{N C}=x y U_{3}\left(s_{3}^{N C}, s_{1}^{I}, s_{2}^{C}\right)+x(1-y) U_{3}\left(s_{3}^{N C}, s_{1}^{I}, s_{2}^{N C}\right)+(1-x) y U_{3}\left(s_{3}^{N C}, s_{1}^{N I}, s_{2}^{C}\right)+(1-x)(1-y) U_{3}\left(s_{3}^{N C}, s_{1}^{N I}, s_{2}^{N C}\right) \\
\bar{\pi}_{3}=z \pi_{3}^{C}+(1-z) \pi_{3}^{N C} \\
\quad=x y z U_{3}\left(s_{3}^{C}, s_{1}^{I}, s_{2}^{C}\right)+x z(1-y) U_{3}\left(s_{3}^{C}, s_{1}^{I}, s_{2}^{N C}\right)+(1-x) y z U_{3}\left(s_{3}^{C}, s_{1}^{N I}, s_{2}^{C}\right) \\
\quad+(1-x)(1-y) z U_{3}\left(s_{3}^{C}, s_{1}^{N I}, s_{2}^{N C}\right)+(1-z) x y U_{3}\left(s_{3}^{N C}, s_{1}^{I}, s_{2}^{C}\right)+x(1-y)(1-z) U_{3}\left(s_{3}^{N C}, s_{1}^{I}, s_{2}^{N C}\right) \\
\quad+(1-z)(1-x) y U_{3}\left(s_{3}^{N C}, s_{1}^{N I}, s_{2}^{C}\right)+(1-z)(1-x)(1-y) U_{3}\left(s_{3}^{N C}, s_{1}^{N I}, s_{2}^{N C}\right)
\end{aligned}
\end{aligned}
$$




$$
\begin{aligned}
\frac{d z}{d t}=z\left(\pi_{3}^{C}-\bar{\pi}_{3}\right) & \\
= & z(1-z)\left[x y\left(U_{3}\left(s_{3}^{C}, s_{1}^{I}, s_{2}^{C}\right)-U_{3}\left(s_{3}^{N C}, s_{1}^{I}, s_{2}^{C}\right)\right)+x(1-y)\left(U_{3}\left(s_{3}^{C}, s_{1}^{I}, s_{2}^{N C}\right)-U_{3}\left(s_{3}^{N C}, s_{1}^{I}, s_{2}^{N C}\right)\right)\right. \\
& +(1-x) y\left(U_{3}\left(s_{3}^{C}, s_{1}^{N I}, s_{2}^{C}\right)-U_{3}\left(s_{3}^{N C}, s_{1}^{N I}, s_{2}^{C}\right)\right) \\
& \left.+(1-x)(1-y)\left(U_{3}\left(s_{3}^{C}, s_{1}^{N I}, s_{2}^{N C}\right)-U_{3}\left(s_{3}^{N C}, s_{1}^{N I}, s_{2}^{N C}\right)\right)\right]
\end{aligned}
$$

Let $F_{3}(x, y, z)=\frac{d z}{d t}$, we discuss 2 situations of the dynamic progress of $z$. Situation 1: When $x=$ $\frac{a_{29}-a_{212}-y\left(a_{16}-a_{13}+a_{26}-a_{23}-a_{112}+a_{19}-a_{212}+a_{29}\right)}{a_{112}-a_{19}-y\left(a_{26}-a_{23}-a_{212}+a_{29}\right)}, F_{3}(x, y, z) \equiv 0$. Situation 1 means $\forall(x, y, z) \in\left\{\Delta S_{i}\right\}_{i \in N}$ is an evolutionary stable point, that is, whether the businesses / the government choose to cooperate / enforce strict restrictions or not, the consumers' strategy will not change over time. Situation 2: When $x \neq$ $\frac{a_{29}-a_{212}-y\left(a_{16}-a_{13}+a_{26}-a_{23}-a_{112}+a_{19}-a_{212}+a_{29}\right)}{a_{112}-a_{19}-y\left(a_{26}-a_{23}-a_{212}+a_{29}\right)}$, let $F_{3}(x, y, z)=0$, we can have $z=0$ or $z=1$.

To further analyze the evolutionary stability strategy, we go further with $F_{3}(z)$ as follows:

$$
\begin{aligned}
\frac{\partial F_{3}(x, y, z)}{\partial z}=[ & x y\left(U_{3}\left(s_{3}^{C}, s_{1}^{I}, s_{2}^{C}\right)-U_{3}\left(s_{3}^{N C}, s_{1}^{I}, s_{2}^{C}\right)\right)+x(1-y)\left(U_{3}\left(s_{3}^{C}, s_{1}^{I}, s_{2}^{N C}\right)-U_{3}\left(s_{3}^{N C}, s_{1}^{I}, s_{2}^{N C}\right)\right) \\
& +(1-x) y\left(U_{3}\left(s_{3}^{C}, s_{1}^{N I}, s_{2}^{C}\right)-U_{3}\left(s_{3}^{N C}, s_{1}^{N I}, s_{2}^{C}\right)\right) \\
& \left.+(1-x)(1-y)\left(U_{3}\left(s_{3}^{C}, s_{1}^{N I}, s_{2}^{N C}\right)-U_{3}\left(s_{3}^{N C}, s_{1}^{N I}, s_{2}^{N C}\right)\right)\right](1-2 z)
\end{aligned}
$$

When $\quad x<\frac{a_{29}-a_{212}-y\left(a_{16}-a_{13}+a_{26}-a_{23}-a_{112}+a_{19}-a_{212}+a_{29}\right)}{a_{112}-a_{19}-y\left(a_{26}-a_{23}-a_{212}+a_{29}\right)},\left.\frac{\partial F_{3}(x, y, z)}{\partial z}\right|_{z=0}<0,\left.\frac{\partial F_{3}(x, y, z)}{\partial z}\right|_{z=1}>0$, thus, $z=0$ is an evolutionary stable point, namely, the government will ultimately choose not to impose strict restrictions.

When $\quad x>\frac{a_{29}-a_{212}-y\left(a_{16}-a_{13}+a_{26}-a_{23}-a_{112}+a_{19}-a_{212}+a_{29}\right)}{a_{112}-a_{19}-y\left(a_{26}-a_{23}-a_{212}+a_{29}\right)},\left.\frac{\partial F_{3}(x, y, z)}{\partial z}\right|_{z=0}>0,\left.\frac{\partial F_{3}(x, y, z)}{\partial z}\right|_{z=1}<0$, thus, $z=1$ is an evolutionary stable point, namely, the government will ultimately choose to impose strict restrictions. We will analyze $y$ in detail in section 4.

Based on the assumption 1, 2 and 3, we can solve $x, y$ and $z$ equations together to find a unique saddle point $\left(x^{*}, y^{*}, z^{*}\right)$ :

$$
\left\{\begin{array}{c}
x=\frac{u_{o}+W_{0}+W-c_{m}^{C}-u_{h}-y\left(2 S^{M}+2 W_{0}\right)}{u_{h}+S_{G}^{C}-u_{o}-W_{0}-W+c_{m}^{C}+c_{p}^{C}-y\left(S^{M}+W_{0}\right)} \\
y=\frac{c_{0}-c_{p}^{C}-c_{p}^{M}-u_{b}-z\left(u_{b}+2 R_{c}-S_{G}^{C}-c_{m}^{G}-c_{p}^{C}-u_{b}\right)}{R_{m}-S_{G}^{M}-c_{c}^{G}+R_{m}-c_{p}^{M}+z\left(c_{c}^{G}+c_{m}^{G}\right)} \\
z=\frac{\pi-W+S^{M}-x c_{p}^{M}}{x c_{p}^{M}-S^{M}-c_{p}^{M}}
\end{array}\right.
$$

Our analysis of the eigenvalues of the Jacobian at each point in Table 3 is equivalent to the analysis of the determinant values and traces of their respective Jacobian matrices. The evolutionary stable points require that the determinant of the Jacobian matrix be less than 0 and the trace is greater than 0 . Table 3 summarizes the determinant values and traces of all equilibrium points in Jacobian matrices.

Table 3. Equilibrium points 


\begin{tabular}{lcc}
$(0,0,0)$ & $a_{17}-a_{27}+a_{22}-a_{28}+a_{212}-a_{29}$ & $\left(a_{17}-a_{27}\right)\left(a_{22}-a_{28}\right)\left(a_{212}-a_{29}\right)$ \\
$(0,0,1)$ & $a_{110}-a_{210}+a_{25}-a_{211}+a_{29}-a_{212}$ & $\left(a_{110}-a_{210}\right)\left(a_{25}-a_{211}\right)\left(a_{29}-a_{212}\right)$ \\
$(0,1,0)$ & $a_{11}-a_{21}+a_{28}-a_{22}+a_{26}-a_{23}$ & $\left(a_{11}-a_{21}\right)\left(a_{28}-a_{22}\right)\left(a_{26}-a_{23}\right)$ \\
$(0,1,1)$ & $a_{14}-a_{24}+a_{211}-a_{25}+a_{23}-a_{26}$ & $\left(a_{14}-a_{24}\right)\left(a_{211}-a_{25}\right)\left(a_{23}-a_{26}\right)$ \\
$(1,0,0)$ & $a_{27}-a_{17}+a_{12}-a_{18}+a_{112}-a_{19}$ & $\left(a_{27}-a_{17}\right)\left(a_{12}-a_{18}\right)\left(a_{112}-a_{19}\right)$ \\
$(1,0,1)$ & $a_{210}-a_{110}+a_{15}-a_{111}+a_{19}-a_{112}$ & $\left(a_{210}-a_{110}\right)\left(a_{15}-a_{111}\right)\left(a_{19}-a_{112}\right)$ \\
$(1,1,0)$ & $a_{21}-a_{11}+a_{18}-a_{12}+a_{16}-a_{13}$ & $\left(a_{21}-a_{11}\right)\left(a_{18}-a_{12}\right)\left(a_{16}-a_{13}\right)$ \\
$(1,1,1)$ & $a_{24}-a_{14}+a_{111}-a_{15}+a_{13}-a_{16}$ & $\left(a_{24}-a_{14}\right)\left(a_{111}-a_{15}\right)\left(a_{13}-a_{16}\right)$ \\
\hline
\end{tabular}

Thus, we follow table 3 to analysis each point. We show whether each point is an evolutionarily stable strategy by the following propositions:

Theorem 1: There are eight possible evolutionary stable strategy: $(0,0,0),(0,0,1),(0,1,0),(0,1,1),(1,0,0),(1,0,1)$, $(1,1,0),(1,1,1)$, if and only if each point satisfies $\operatorname{det} J>0$ and $\operatorname{tr} J>0$.

\section{Proof. See Appendix A.1}

We first describe the replicate dynamic trajectories of the saddle points. The dynamic trajectory will show the direction of motion of the midpoint in different regions, which is of great significance when analyzing the phase diagram later. Similarly, we analyze the Jacobian matrix eigenvalues of each point in Table 2 to judge the existence of ESS points. Fig. 1, Fig. 2, and Fig. 3 illustrate the dynamic process of saddle point replication. The solid arrow line represents convergence to 1 , and the dashed arrow line represents convergence to 0 .
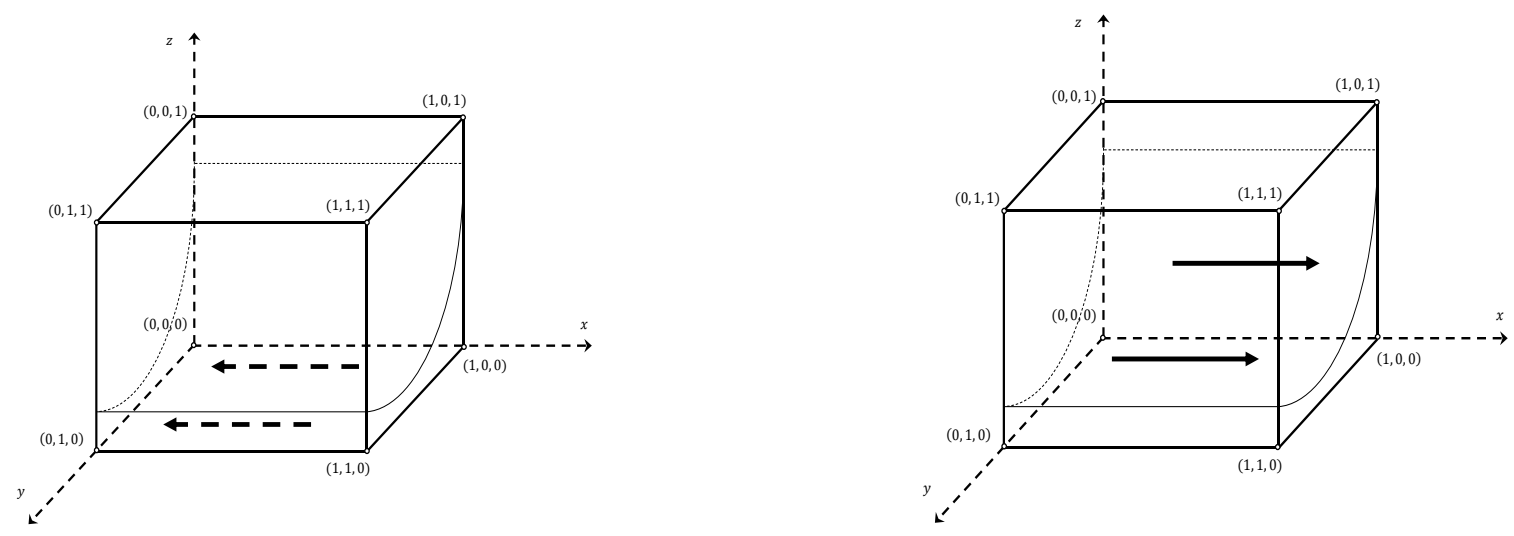

Figure 1. When $y \neq \frac{a_{27}-a_{17}-z\left(a_{110}-a_{210}-a_{17}+a_{27}\right)}{a_{11}-a_{21}-a_{17}+a_{27}+z\left(a_{17}-a_{27}+a_{14}-a_{24}-a_{11}+a_{21}-a_{110}+a_{210}\right)}$, replicate dynamic trajectories of $x$. 

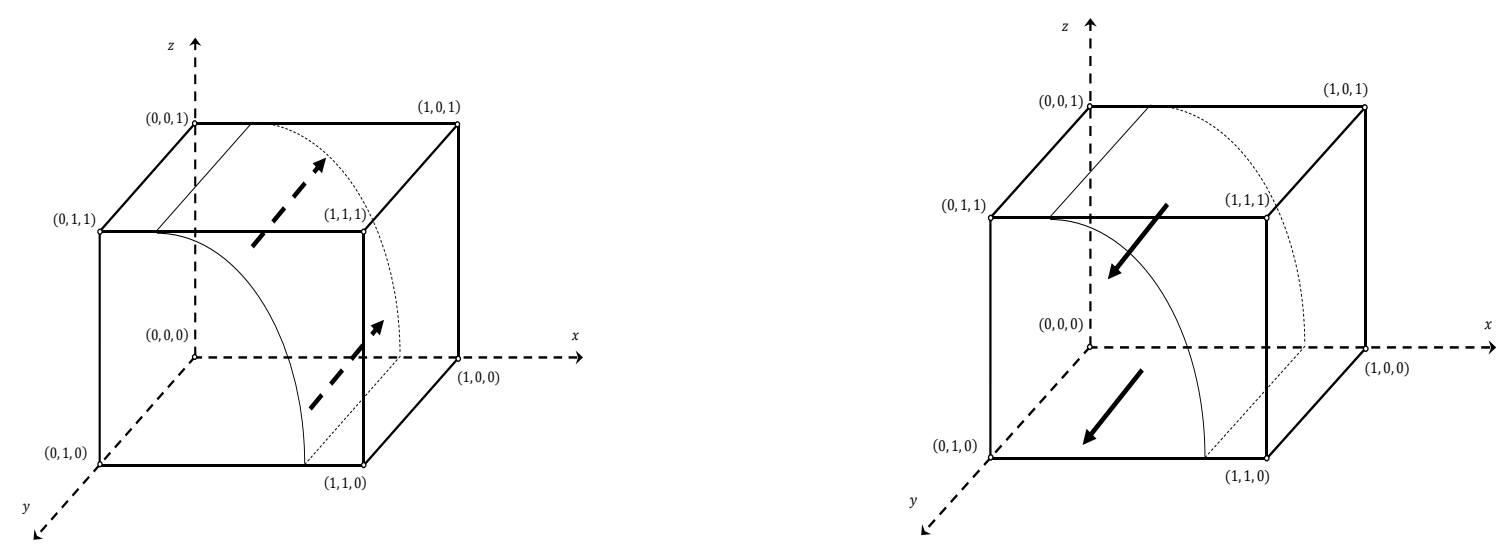

Figure 2. When $z \neq \frac{a_{28}-a_{25}-x\left(a_{12}-a_{18}-a_{22}+a_{28}\right)}{x\left(a_{15}-a_{111}+a_{22}-a_{28}-a_{25}+a_{211}\right)+a_{25}-a_{211}-a_{12}+a_{18}-a_{22}+a_{28}}$, replicate dynamic trajectories of $y$
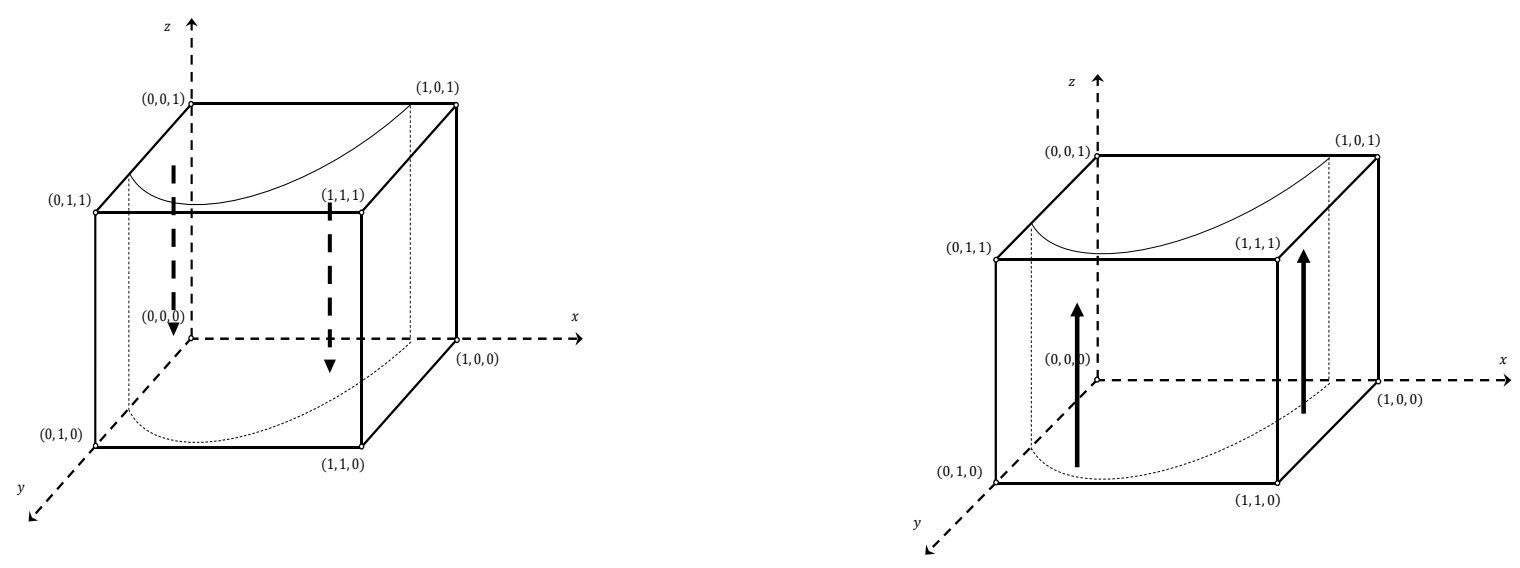

Figure 3. When $x \neq \frac{a_{29}-a_{212}-y\left(a_{16}-a_{13}+a_{26}-a_{23}-a_{112}+a_{19}-a_{212}+a_{29}\right)}{a_{112}-a_{19}-y\left(a_{26}-a_{23}-a_{212}+a_{29}\right)}$, replicate dynamic trajectories of $z$.

Table 3 describes the equilibrium points that may become evolutionarily stable strategies. We divide the space into 8 regions with $\left(x^{*}, y^{*}, z^{*}\right)$ as the center: I , II, III, IV, V, VI, VII and VIII. Figure 4 reflects the 8 regions in the space. Table 4 shows the subspace names that each region represent. 


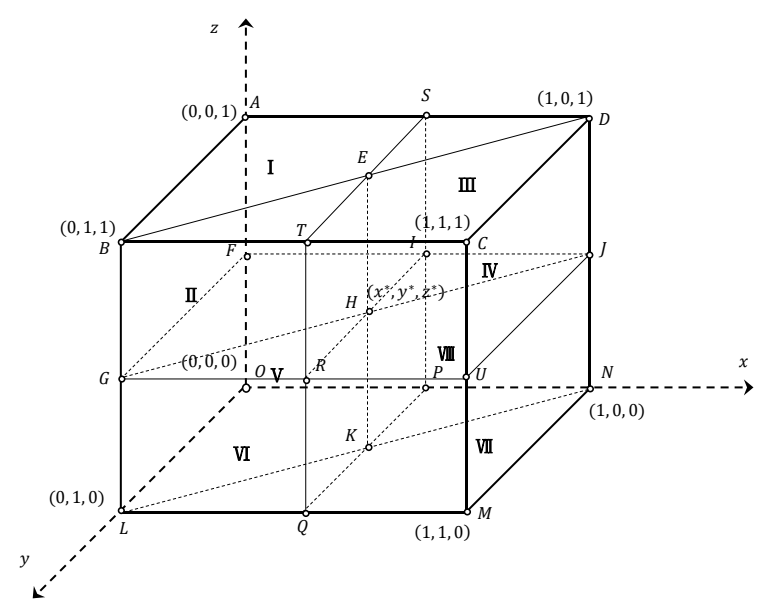

Figure 4. 8 different subspaces.

Table 4. Subspace description of each part

\begin{tabular}{c|c}
\hline Region & Subspace description \\
\hline I & Hexahedron $A$ BESIHGF \\
II & Pentahedron BETRHG \\
III & Pentahedron SEHIJD \\
IV & Hexahedron EDCTRUJH \\
V & Hexahedron FGHIPKLO \\
VI & Pentahedron GRHKQL \\
VII & Hexahedron HRUJNMQK \\
VII & Pentahedron IHKPNJ \\
\hline
\end{tabular}

We will use propositions 1 to 7 to answer the two research questions of this paper.

We further analyzed the four ESS points described above. When $0<x<x^{*}, 0<y<y^{*}$ and $0<z<z^{*}$, We first analyze the replicate dynamic process when the initial point is in I (Hexahedron ABESIHGF). Figure 5. shows the dynamic trajectory when the initial point is in I . 


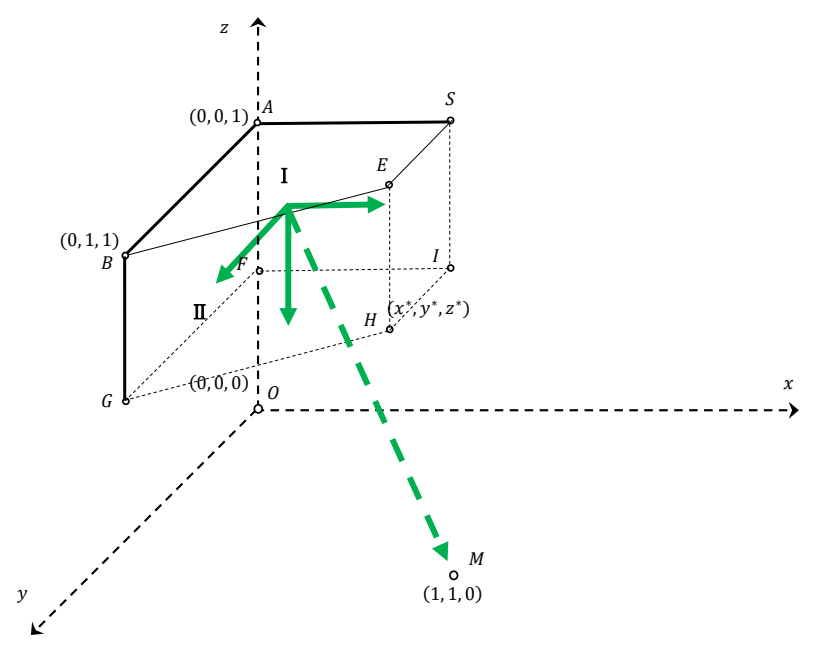

Figure 5. Dynamic trajectory when the initial point is in region I .

Proposition 1: If the position of the initial point is in region I, namely, $x \in\left(0, x^{*}\right), y \in\left(y^{*}, 1\right)$ and $z \in\left(z^{*}, 1\right),(x, y, z)$ will convergence to the point $(1,1,0) .(1,1,0)$ will be the ESS, if and only if it satisfies the condition:

$$
\frac{c_{p}^{C}}{S_{G}^{C}+S^{M}}=\emptyset
$$

\section{See Appendix A.2 for the proof of proposition 1}

$(1,1,0)$ is ESS, meaning that businesses, and consumers were support for active prevention while the government did not choose to implement the restrictive policies at the beginning. Eventually the government will impose strict restrictions, and businesses will cooperate with the government. However, in the end, consumers will give up fighting the pandemic. They believe that the net benefit to their health is less than their other net utility. Consumers do not support active prevention when the government supports, $\frac{c_{p}^{C}}{S_{G}^{C}+S^{M}} \neq \emptyset$. Thus, the condition contradicts with our assumption, and $(1,1,0)$ is not the ESS.

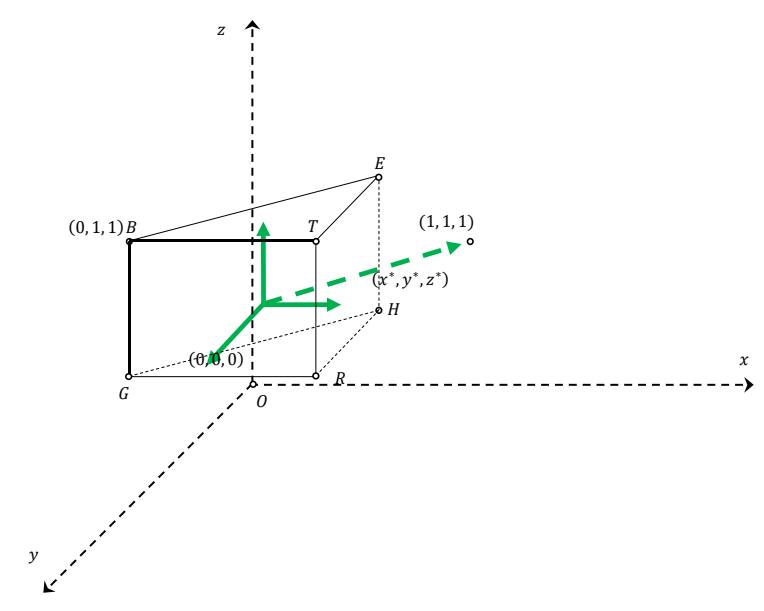

Figure 6. Dynamic trajectory when the initial point is in region II . 
Proposition 2: If the position of the initial point is in region II (Pentahedron BETRHG), namely, $x \in\left(x^{*}, 1\right), y \in\left(y^{*}, 1\right)$ and $z \in\left(z^{*}, 1\right),(x, y, z)$ will convergence to the point $(1,1,1) .(1,1,1)$ will be the ESS, if and only if it satisfies the condition:

$$
\left\{\begin{array}{c}
\frac{c_{p}^{M}+S^{M}}{S_{G}^{M}} \in \emptyset \\
\frac{c_{p}^{C}}{S_{G}^{C}+S^{M}} \in[0,+\infty) \\
u_{b}+2 R_{M}+2 R_{C}^{a}-c_{0}-S_{G}^{M}-S_{G}^{C}<0
\end{array}\right.
$$

\section{See Appendix A.3 for the proof of proposition 2}

Figure 6. shows the dynamic trajectory when the initial point is in II. When initial point in region II, Strict restrictions are initially supported by a large minority of the government, businesses and consumers. In the end, the government, businesses, and consumers agree that fighting the pandemic is necessary from the start. In other words, the whole society has formed a united active prevention front. The government has an incentive to implement strict active prevention measures as long as the net utility of strict restrictions implemented by the government is not equal to the utility of doing nothing at all. Only if $u_{b}+2 R_{M}+2 R_{C}^{a}-c_{0}-S_{G}^{M}-S_{G}^{C}<0$, We can implement the punishment mechanism under $(1,1,1):\left\{\begin{array}{c}\frac{c_{p}^{M}+S^{M}}{S_{G}^{M}} \in \emptyset \\ \frac{c_{p}^{C}}{S_{G}^{C}+S^{M}} \in[0,+\infty)\end{array}\right.$. Since all participants support fighting the pandemic, we allow $\frac{c_{p}^{M}+S^{M}}{S_{G}^{M}} \in \emptyset$. The government, businesses and consumers will eventually form a unified active prevention front.

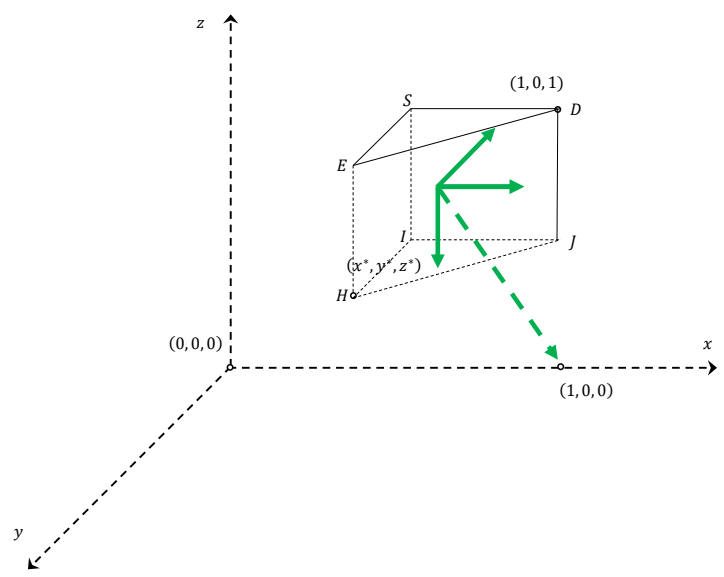

Figure 7. Dynamic trajectory when the initial point is in region III

Proposition 3: If the position of the initial point is in region III (Pentahedron SEHIJD), namely, $x \in\left(0, x^{*}\right), y \in\left(y^{*}, 1\right)$ and $z \in\left(0, z^{*}\right),(x, y, z)$ will convergence to the point $(1,0,0) .(1,0,0)$ will be the ESS, if and only if it satisfies the condition:

$$
\begin{aligned}
& \left\{\begin{array}{c}
\frac{c_{p}^{C}}{S_{G}^{C}+S^{M}} \in\left(\frac{c_{0}-u_{b}-c_{p}^{M}+R_{M}+R_{C}^{r}}{S_{G}^{C}+S^{M}},+\infty\right) \cap\left(0, \frac{u_{o}+W_{0}+W-c_{m}^{C}-u_{h}-S_{G}^{C}}{S_{G}^{C}+S^{M}}\right) \cup\left(\frac{u_{o}+W_{0}+W-c_{m}^{C}-u_{h}-S_{G}^{C}}{S_{G}^{C}+S^{M}},+\infty\right) \cap\left(0, \frac{c_{0}-u_{b}-c_{p}^{M}+R_{M}+R_{C}^{r}}{S_{G}^{C}+S^{M}}\right) \\
\frac{c_{p}^{M}+S^{M}}{S_{G}^{M}} \in\left(\frac{s^{M}}{S_{G}^{M}}, \frac{u_{o}+W_{0}+W+c_{0}-2 c_{p}^{C}-u_{b}-u_{h}-S_{G}^{C}-c_{m}^{C}+2 S^{M}+R_{M}+R_{C}^{r}}{2 S_{G}^{M}}\right)
\end{array}\right. \\
& c_{0}-u_{b}-c_{p}^{M} \neq u_{o}+W_{0}+W-c_{m}^{C}-u_{h}-S_{G}^{C}
\end{aligned}
$$

\section{See Appendix A.4 for the proof of proposition 3}


Figure 7. shows the dynamic trajectory when the initial point is in III. When the initial point is in region III, the consumers support the implementation of a strict active prevention policy. Most people in the government and in businesses initially do not support strict restrictions. Since the initial point will converge to $(1,0,0)$, that is, there will be only the government supporting active prevention policies while the businesses and consumers will not support active prevention actions in the end. According to the conditions that make $(1,0,0)$ be the ESS, the punishment mechanism is as follows:

$$
\left\{\begin{array}{c}
\frac{c_{p}^{C}}{S_{G}^{C}+S^{M}} \in\left(\frac{c_{0}-u_{b}-c_{p}^{M}+R_{M}+R_{C}^{r}}{S_{G}^{C}+S^{M}},+\infty\right) \cap\left(0, \frac{u_{o}+W_{0}+W-c_{m}^{C}-u_{h}-S_{G}^{C}}{S_{G}^{C}+S^{M}}\right) \cup\left(\frac{u_{o}+W_{0}+W-c_{m}^{C}-u_{h}-S_{G}^{C}}{S_{G}^{C}+S^{M}},+\infty\right) \cap\left(0, \frac{c_{0}-u_{b}-c_{p}^{M}+R_{M}+R_{C}^{r}}{S_{G}^{C}+S^{M}}\right) . \\
\frac{c_{p}^{M}+S^{M}}{S_{G}^{M}} \in\left(\frac{S^{M}}{S_{G}^{M}}, \frac{u_{o}+W_{0}+W+c_{0}-2 c_{p}^{C}-u_{b}-u_{h}-S_{G}^{C}-c_{m}^{C}+2 S^{M}+R_{M}+R_{C}^{r}}{2 S_{G}^{M}}\right)
\end{array} .\right.
$$

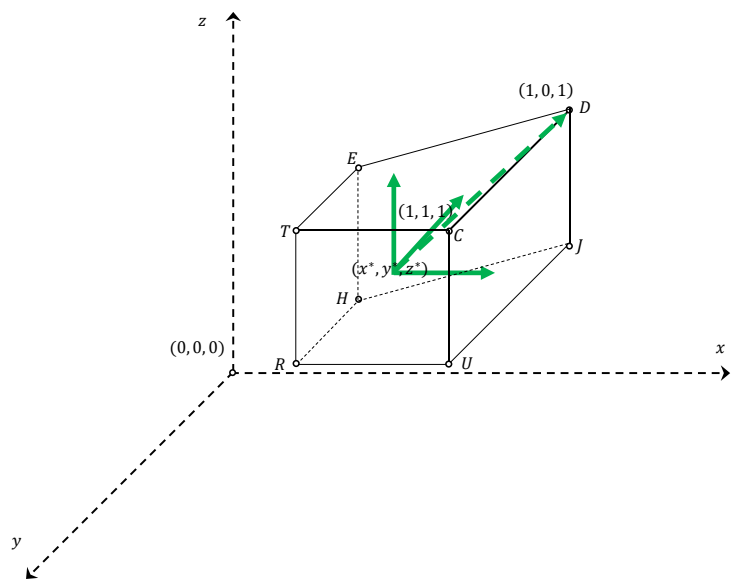

Figure 8. Dynamic trajectory when the initial point is in region IV

Proposition 4: If the position of the initial point is in region IV (Hexahedron EDCTRUJH), namely, $x \in\left(x^{*}, 1\right), y \in$ $\left(y^{*}, 1\right)$ and $z \in\left(0, z^{*}\right),(x, y, z)$ will convergence to the point $(1,0,1) .(1,0,1)$ will be the ESS, if and only if it satisfies the condition:

$\frac{c_{p}^{M}+S^{M}}{S_{G}^{M}} \in \varnothing$

\section{See Appendix A.5 for the proof of proposition 4}

Although point $(1,0,1)$ is theoretically an ESS, we assume that businesses or consumers will be punished if they do not cooperate when the government imposes strict restrictions: $\frac{c_{p}^{M}+S^{M}}{S_{G}^{M}} \notin \emptyset$. Thus, the condition contradicts our assumptions. $(1,0,1)$ is not an ESS.

Proposition 5: $(0,0,0)$ and $(0,1,0)$ are not the ESS.

See Appendix A.6 for the proof of proposition 5 


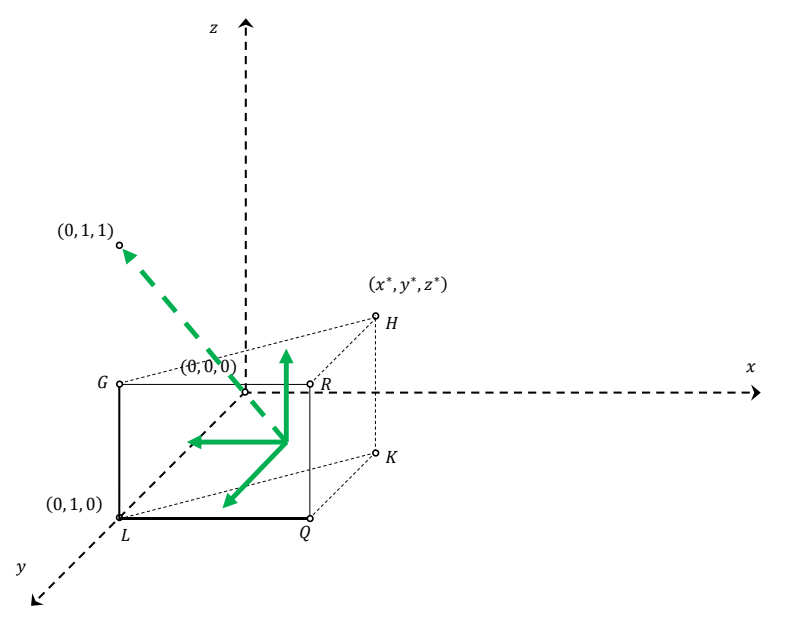

Figure 9. Dynamic trajectory when the initial point is in region VI

Proposition 6: If the position of the initial point is in region VI (Pentahedron GRHKQL), namely, $x \in\left(x^{*}, 1\right), y \in\left(0, y^{*}\right)$ and $z \in\left(z^{*}, 1\right),(x, y, z)$ will convergence to the point $(0,1,1) \cdot(0,1,1)$ will be the ESS, if and only if it satisfies the condition:

$$
\left\{\begin{array}{c}
\frac{S^{M}+c_{p}^{M}}{S_{G}^{M}} \in\left(\frac{c_{p}^{M}}{S_{G}^{M}}, \frac{u_{o}+W-c_{m}^{C}-u_{h}+c_{p}^{M}}{S_{G}^{M}}\right) \\
\frac{S_{G}^{M}+S_{G}^{C}}{c_{p}^{M}+c_{p}^{C}} \in\left(\frac{u_{b}+2 R_{M}+2 R_{C}^{a}-c_{0}+u_{o}+W-c_{m}^{C}-u_{h}}{c_{p}^{M}+c_{p}^{C}}, \frac{u_{b}+2 R_{M}+2 R_{C}^{a}-c_{0}}{c_{p}^{M}+c_{p}^{C}}\right)
\end{array}\right.
$$

\section{See Appendix A.7 for the proof of proposition 6}

Figure 9. shows the dynamic trajectory when the initial point is in VI. In the beginning, the government and consumers supported strict active prevention policies, but businesses did not. However, in the end, businesses and consumers will support strict active prevention measures, while the government will not impose strict restrictions. The changing attitude of the government results in no penalty costs in this situation. Therefore, we believe that the likely cause of the change of attitude of the government is the excessive subsidy. According to the Proposition 6, the subsidy mechanism is as follows: $\left\{\begin{array}{c}\frac{S^{M}+c_{p}^{M}}{S_{G}^{M}} \in\left(\frac{c_{p}^{M}}{S_{G}^{M}}, \frac{u_{o}+W-c_{m}^{C}-u_{h}+c_{p}^{M}}{S_{G}^{M}}\right) \\ \frac{S_{G}^{M}+S_{G}^{C}}{c_{p}^{M}+c_{p}^{C}} \in\left(\frac{u_{b}+2 R_{M}+2 R_{C}^{a}-c_{0}+u_{o}+W-c_{m}^{C}-u_{h}}{c_{p}^{M}+c_{p}^{C}}, \frac{u_{b}+2 R_{M}+2 R_{C}^{a}-c_{0}}{c_{p}^{M}+c_{p}^{C}}\right)\end{array}\right.$
$u_{h}<0$. 


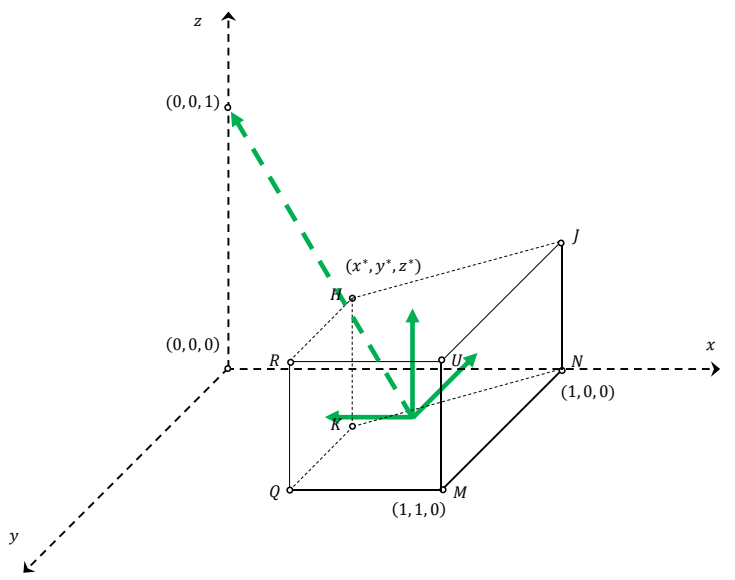

Figure 10. Dynamic trajectory when the initial point is in region VII

Proposition 7: If the position of the initial point is in region VII (Hexahedron $\operatorname{HRUJNMQK}$ ), namely, $x \in\left(x^{*}, 1\right), y \in$ $\left(0, y^{*}\right)$ and $z \in\left(0, z^{*}\right),(x, y, z)$ will converge to the point $(0,0,1) .(0,0,1)$ will be the ESS, if and only if it satisfies the condition:

$\left\{\frac{c_{p}^{M}+S^{M}}{S_{G}^{M}} \in\left(\frac{c_{p}^{M}}{S_{G}^{M}},+\infty\right) \cap\left(\frac{S_{G}^{C}+c_{0}+c_{M}^{G}-u_{b}-2 R_{C}^{a}+S^{M}}{S_{G}^{M}}, \frac{S_{G}^{C}+c_{0}+c_{M}^{G}+S^{M}+c_{m}^{C}+u_{h}-u_{o}-W_{0}-W-u_{b}-2 R_{C}^{a}+S^{M}}{S_{G}^{M}}\right) \cap\left[\frac{S^{M}}{S_{G}^{M}}, \frac{S_{G}^{C}+c_{0}+c_{M}^{G}-u_{b}-2 R_{C}^{a}+S^{M}}{S_{G}^{M}}\right)\right.$

\section{See Appendix A.8 for the proof of proposition 7}

Figure 10. shows the dynamic trajectory when the initial point is in VII. In the beginning, the government has high probability of deciding to implement strict active prevention policies, while consumers and businesses have low probability to break them. Finally, governments and businesses will have no incentive to implement rigorous active prevention action, while consumers will choose active prevention. In this situation, the subsidy mechanism is: $\frac{c_{p}^{M}+s^{M}}{S_{G}^{M}} \in$ $\left(\frac{c_{m}^{M}}{S_{G}^{M}},+\infty\right) \cap\left(\frac{S_{G}^{C}+c_{0}+c_{M}^{G}-u_{b}-2 R_{C}^{a}+S^{M}}{S_{G}^{M}}, \frac{s_{G}^{C}+c_{0}+c_{M}^{G}+S^{M}+c_{m}^{C}+u_{h}-u_{0}-W_{0}-W-u_{b}-2 R_{C}^{a}+S^{M}}{S_{G}^{M}}\right) \cap\left[\frac{S^{M}}{S_{G}^{M}}, \frac{S_{G}^{C}+c_{0}+c_{M}^{G}-u_{b}-2 R_{C}^{a}+S^{M}}{S_{G}^{M}}\right)$.

To sum up, we conclude four ESS points: $(0,0,1),(0,1,1),(1,0,0)$ and $(1,1,1)$. Table 4 shows the final ESS points. By establishing propositions 1-7, we have answered the research questions of this paper: Q1: Whether there is a strategy profile that enables the government, businesses, and consumers to meet their respective utility maximization during COVID-19. We find four ESS points: $(0,0,1),(0,1,1),(1,0,0)$ and $(1,1,1)$. Thus, in the long term, the following four equilibrium strategy profiles can be chosen for the government, businesses, and consumers to meet their respective utility maximization.

1. For $(0,0,1)$, the final equilibrium strategy profile is the following: only consumers will choose to active fight the pandemic. The government and businesses will give up fighting COVID-19. At beginning, the government has a high probability of deciding to implement strict active prevention policies, while consumers and businesses have a low probability of cooperating. In the process, from the initial strategy choice of the government, businesses and consumers to their final strategy choice, businesses never agree to fight the pandemic while the strategy choice of the government and consumers changes over time.

2. For $(0,1,1)$, the final equilibrium strategy profile is the following: In the end, the government will not choose a strict active prevention strategy, but businesses and consumers will take preventive measures. From the initial choice to the final choice, consumers always fight the pandemic. The choices of the government and businesses, however, do change: government moves from actively battling the pandemic to giving up; businesses take the inverse path.

3. For $(1,0,0)$, the final equilibrium strategy profile is the following: Eventually, only the government will fight the 
pandemic while businesses and consumers will give up. In this case, consumer have the same strategy throughout but government and business change their initial strategy.

4. For $(1,1,1)$, the final equilibrium strategy profile is the following: In the end, the government, businesses, and consumers form a united front against the pandemic. The initial attitude of the government, businesses, and consumers in the fight against the pandemic is consistent with their final attitude.

The dynamic process of the above four points answers the first research question of this paper. We also have answered the second research question in this paper according to propositions 1 to 7. Q2: Whether penalty and subsidy mechanisms can influence the strategy profiles of governments, businesses, and consumers during COVID-19? Different convergence points correspond to different subsidy and penalty mechanisms, namely, if these corresponding subsidiary-penalty mechanisms are satisfied, the corresponding final combination of strategies will be realized. We summarize those subsidy-penalty mechanisms as follows:

1. If the government, businesses, and consumers choose $(0,0,1)$ as the final strategy profile, the range of subsidypunishment ratio is as follows: $\frac{c_{c}^{M}+S^{M}}{S_{G}^{M}} \in\left(\frac{c_{p}^{M}}{S_{G}^{M}},+\infty\right) \cap\left(\frac{S_{G}^{C}+c_{0}+c_{m}^{G}-u_{b}-2 R_{c}+S^{M}}{S_{G}^{M}}, \frac{S_{G}^{C}+c_{0}+c_{m}^{G}+S^{M}+c_{m}^{C}+u_{b}-u_{0}-W_{0}-W-u_{b}-2 R_{c}+S^{M}}{S_{G}^{M}}\right) \cap\left[\frac{S^{M}}{S_{G}^{M}} \frac{S_{G}^{C}+c_{0}+c_{m}^{G}-u_{b}-2 R_{c}+S^{M}}{S_{G}^{M}}\right)$

2. If the government, businesses, and consumers choose $(0,1,1)$ as the final strategy profile, the range of subsidypunishment ratio is as follows: $\left\{\begin{array}{c}\frac{s^{M}+c_{p}^{M}}{s_{G}^{M}} \in\left(\frac{c_{p}^{M}}{S_{G}^{M}}, \frac{u_{o}+W-c_{m}^{C}-u_{h}+c_{p}^{M}}{S_{G}^{M}}\right) \\ \frac{s_{G}^{M}+S_{G}^{C}}{c_{p}^{M}+c_{p}^{C}} \in\left(\frac{u_{b}+2 R_{m}+2 R_{C}-c_{0}+u_{o}+W-c_{m}^{C}-u_{h}}{c_{p}^{M}+c_{p}^{C}}, \frac{u_{b}+2 R_{m}+2 R_{C}-c_{0}}{c_{p}^{M}+c_{p}^{C}}\right)\end{array}\right.$.

3. If the government, businesses, and consumers choose $(1,0,0)$ as the final strategy profile, the range of subsidypunishment ratio is as follows: $\left\{\begin{array}{c}\frac{c_{p}^{C}}{S_{G}^{C}+S^{M}} \in\left(\frac{c_{0}-u_{b}-c_{p}^{M}}{S_{G}^{C}+S^{M}},+\infty\right) \cap\left(0, \frac{u_{o}+W_{0}+W-c_{m}^{C}-u_{h}-S_{G}^{C}}{S_{G}^{C}+S^{M}}\right) \cup\left(\frac{u_{o}+W_{0}+W-c_{m}^{C}-u_{h}-S_{G}^{C}}{S_{G}^{C}+S^{M}},+\infty\right) \cap\left(0, \frac{c_{0}-u_{b}-c_{p}^{M}}{S_{G}^{C}+S^{M}}\right) \\ \frac{c_{p}^{M}+S^{M}}{S_{G}^{M}} \in\left(\frac{s^{M}}{S_{G}^{M}}, \frac{u_{o}+W_{0}+W+c_{0}-2 c_{p}^{C}-u_{b}-u_{h}-S_{G}^{C}-c_{m}^{C}+S^{M}}{2 S_{G}^{M}}\right) \cup\left(\frac{s^{M}}{S_{G}^{M}}, \frac{u_{o}+W_{0}+W+c_{0}-2 c_{p}^{C}-u_{b}-u_{h}-S_{G}^{C}-c_{m}^{C}+S^{M}}{2 S_{G}^{M}}\right)\end{array}\right.$.

4. If the government, businesses, and consumers choose $(1,1,1)$ as the final strategy profile, the range of subsidypunishment ratio is as follows: $\left\{\begin{array}{c}\frac{c_{p}^{M}+S^{M}}{S_{G}^{M}} \in \emptyset \\ \frac{c_{p}^{C}}{S_{G}^{C}+S^{M}} \in[0,+\infty)\end{array}\right.$.

These subsidy and punishment mechanisms influence the decisions of governments, businesses, and consumers through their range of values. If punishment is too low, and businesses and consumers have no incentive to comply. Low subsidies also produce weak incentives for businesses and consumers to choose to fight the pandemic. Therefore, subsidy and punishment should be set within a reasonable range to effectively motivate businesses and consumers. High subsidies, however, weaken the incentive for the government to implement policies as these come with high fiscal cost. This is likely to be especially relevant to less developed countries. Table 5 shows the evolutionary stable strategy points.

Table 5. Evolutionary stable strategy points 
$(0,1,1)$

$(1,1,1)$
ESS

ESS

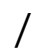

/

ESS

\subsection{Numerical analysis}

We perform numerical analysis using Matlab on the above four ESS points. We analyze the parameters based on our observation of the situation of different countries during COVID-19 as the basis for the value of each parameter. We will use the above evolutionary game theoretic conclusions to compare the situations of Japan and India (We selected these two countries for comparison because Japan achieved good results in the two waves of COVID-19 while India was relatively successful in the first wave and unsuccessful in the second. This aligns with Situations 1 and 2 mentioned in the introduction).

The Japanese government's initial response to the COVID-19 outbreak was to adopt a containment policy. On January 24, 2020, it announced that it would coordinate with National Institute of Infectious Diseases (NIID) to propose appropriate policies to prevent and control the disease. On January 27, 2020, in accordance with the Quarantine Law, those suspected of being infected were quarantined with testing and treatment mandated. The Japanese government has prioritized the establishment of COVID-19 testing and counselling systems based on the NIID. In addition, it has set up a dedicated consultation center for COVID-19 and has promised to provide a large quantity of testing reagents. The Japanese government has decided that prevention of mass clusters of disease in Japan will be a priority in its disease response, such as suspending mass gatherings, community events, school operations and restricting access to medical facilities by patients with mild cold symptoms to prevent them from taking up hospital resources. The government also urged companies to allow employees to work from home or commute during off-peak hours. The government has also formally asked local governments and companies to cancel major events.

On February 12, 2020, the Japanese government announced that it would provide $¥ 500$ billion in emergency loans and loan guarantees for small and medium-sized businesses affected by COVID-19. It also announced that the cabinet would allocate 15.3 billion yen from the emergency fund to facilitate the donation of isolated virus samples to relevant research institutions around the world. On March 10, 2020, a second emergency plan was announced, focused on increasing hospital beds for infected patients, increasing loan support for businesses, and strengthening employment support. As a special measure implemented from April 1 to December 31, the Ministry of Labor and Welfare has offered leave subsidies of up to 100 percent for small and medium-sized businesses and up to 80 percent for large businesses. The allowance for each employee on leave was capped at $¥ 15,000$ per day. This supplemental income policy has caused problems. When the $¥ 300,000$ per household policy was changed to a ¥100,000 per household population policy, it encountered many obstacles. The Japanese government has organized an emergency plan to use a reserve fund of 270 billion yen ( $\$ 2.5$ billion) for the fiscal year ending March 2021 to contain the virus and minimize its impact on the economy.

Japan has been praised for keeping the number of infections low without having to enforce strict rules. As the number of infected people soared, the Japanese government began to rethink the so-called "Japanese model" of voluntary compliance in early November 2020. In February 2021 legislation was introduced to fine those who violate social distancing rules.

Kaori et al. (2020) studied the changes in the behavior of Japanese citizens during COVID-19 due to the implementation of restrictive measures by the Japanese government. They found that about most people reported taking governmentrecommended distance measures, with women and older people more likely to cooperate. However, the results of the study also showed that about 20 percent of participants were reluctant to take proper precautions. 
Based on the above observations in Japan, we assume the basic parameters value: $R_{M}=0.25 ; R_{c}^{a}=0.6 ; R_{C}^{r}=0.35$; $u_{b}=0.5 ; c_{0}=0.5 ; c_{C}^{G}=0.15 ; c_{M}^{G}=0.15 ; u_{h}=0.75 ; u_{o}=0.45 ; W=0.25 ; c_{m}^{C}=0.45 ; W_{0}=0.2 ; c_{p}^{C}=0.15 ; S_{G}^{M}=$ $0.85 ; S_{G}^{C}=0.85 ; c_{p}^{M}=0.15 ; S^{M}=0.1$. Figure 11 (a) shows a possible evolutionary stable strategy for Japan; Figure 11 (b) shows the Japan's ultimate evolutionary stable strategy, based on the initial actual attitude of the Japanese government and citizens to fight the epidemic.

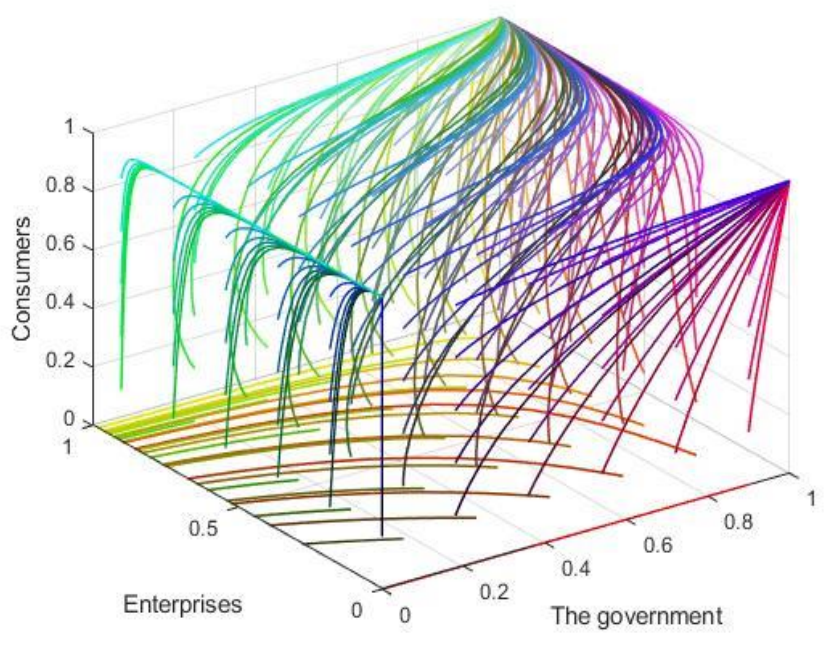

Figure 11 (a). Possible evolutionary stable strategies for Japan, when $S_{G}^{M}<$ 0.75 and $S_{G}^{C}<0.75$

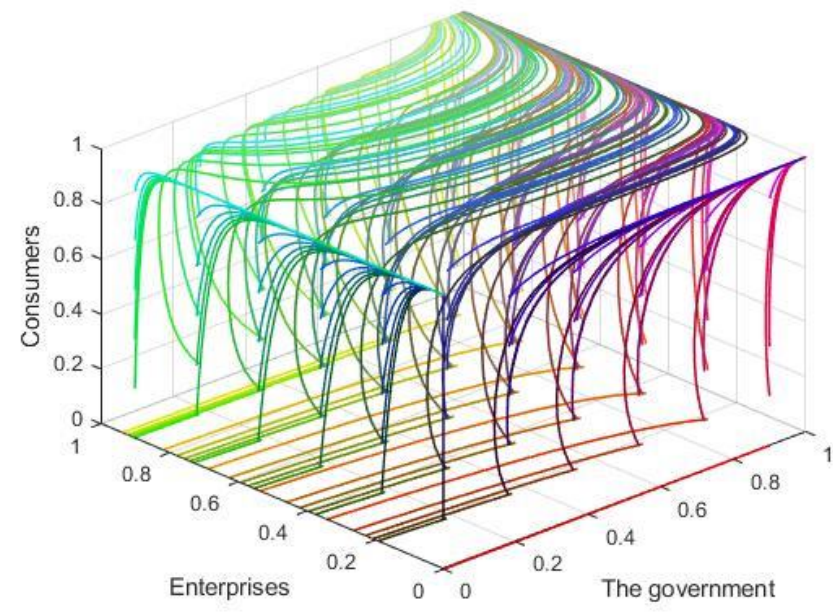

Figure 12 (a). Possible evolutionary stable strategies for Japan, when $S_{G}^{M} \geq$ 0.75 and $S_{G}^{C} \geq 0.75$.

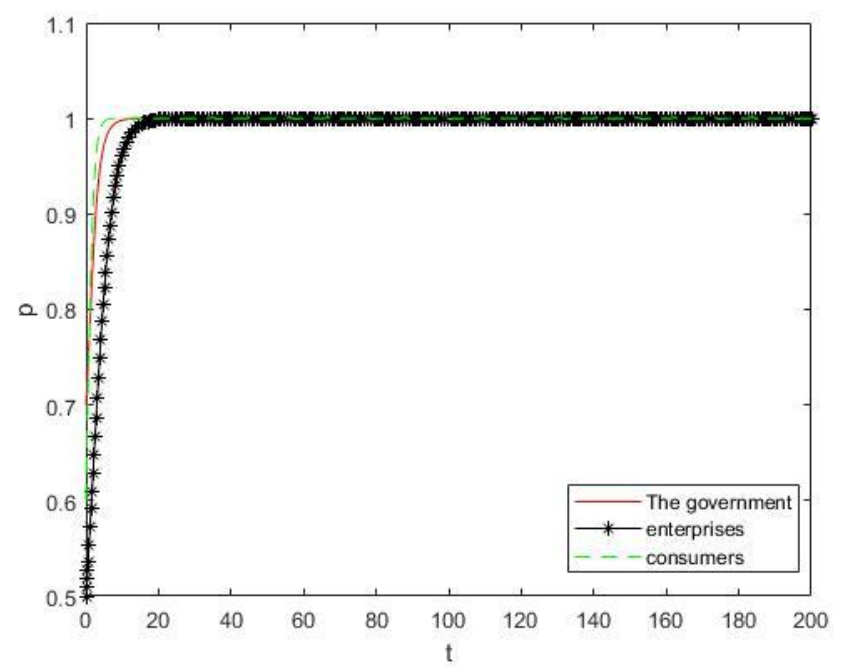

Figure 11 (b) Japan's ultimate evolutionary stable strategy, when $S_{G}^{M}<0.75$ and $S_{G}^{C}<0.75$.

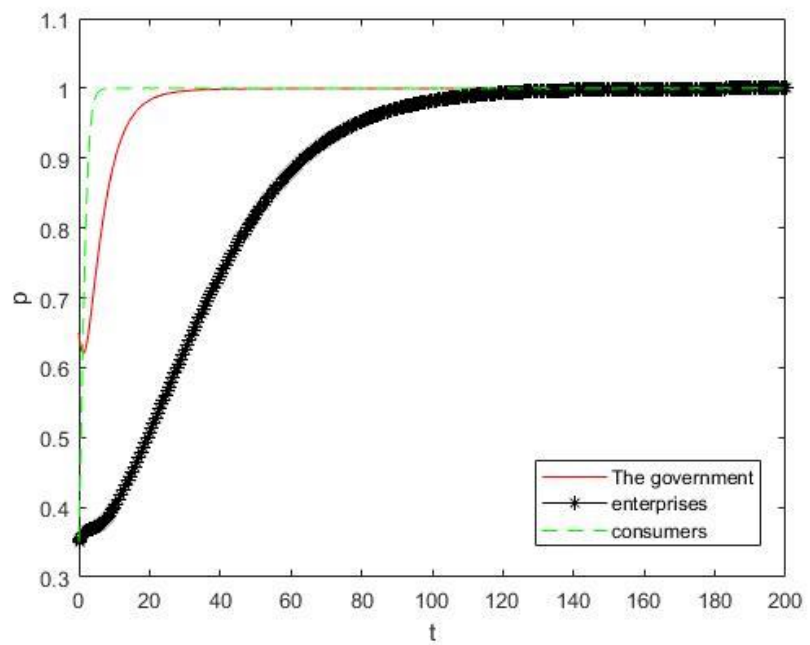

Figure 12 (b) Japan's ultimate evolutionary stable strategy, when $S_{G}^{M} \geq 0.75$ and $S_{G}^{C} \geq 0.75$

It is not difficult to find from Figure 11 (a) that Japan may have two evolutionary stable strategies: $(1,1,1)$ and $(1,0,1)$. The government has chosen a profile of high subsidies and low penalties. This policy profile suits Japan's circumstances, called "Japanese model" of voluntary compliance. Therefore, such a policy profile can form a situation of united antipandemic action, namely $(1,1,1)$. From Figure $10(\mathrm{~b})$, we see a short time $(t$, on the horizontal axis) convergence to a high probability ( $p$, on the vertical axis) of all actors fighting the pandemic. Consumers and businesses converge to 1 
faster than government in our simulation, which matches the actual situation in Japan. From figure 12 (a) and 12(b), we also can find those three probabilities will eventually convergence to 1, when the subsidy is at a high level. Therefore, no matter how high the Japanese government setting the subsidy level, it cannot influence the eventually convergency. It also implies that the Japanese subsidy system only affects how quickly the Japanese government, businesses, and consumers act, not whether they will act.

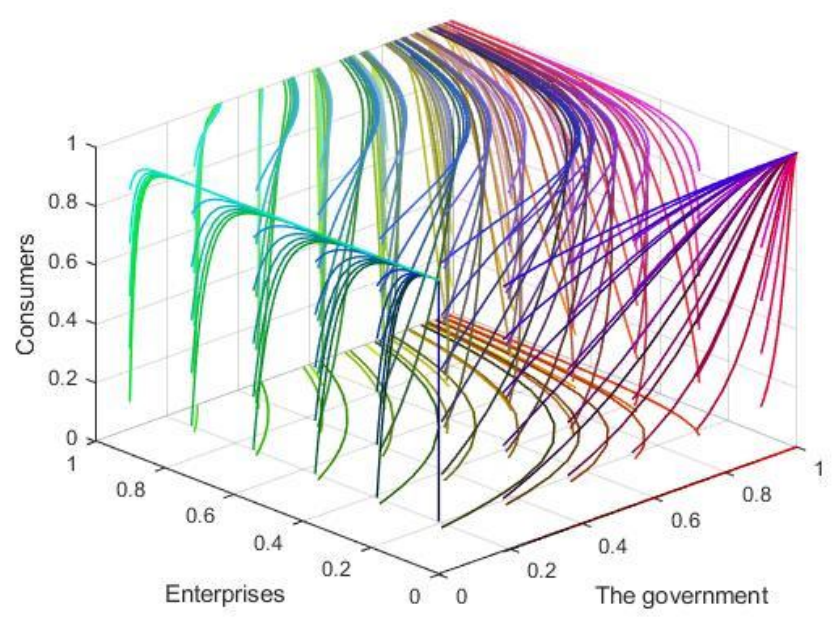

Figure 13 (a). Possible evolutionary stable strategies for Japan, when $c_{p}^{M} \geq$ 0.75 and $c_{p}^{C} \geq 0.75$

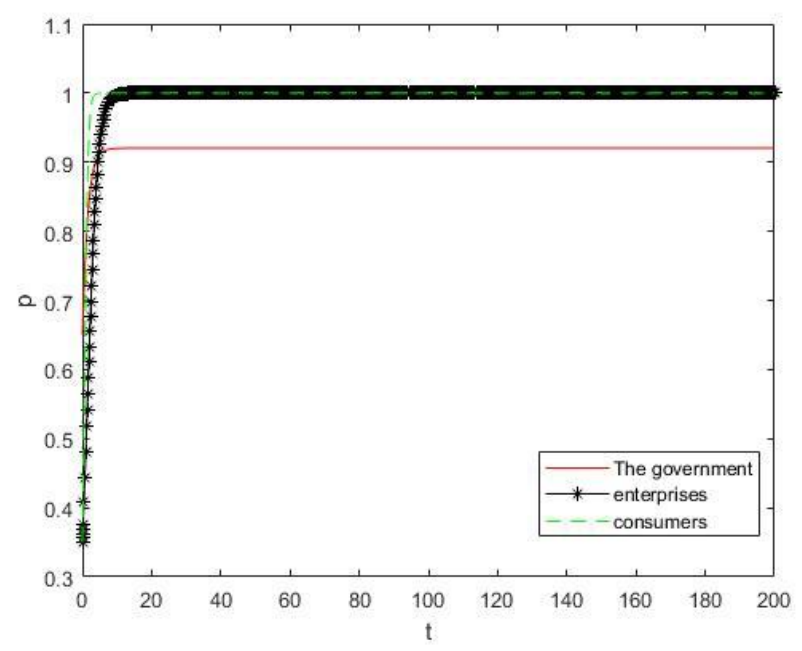

Figure 13 (b) Japan's ultimate evolutionary stable strategy, when $c_{p}^{M} \geq 0.75$ and $c_{p}^{C} \geq 0.75$.

As mentioned above, the Japanese government began to rethink the so-called "Japanese model" of voluntary compliance in early November 2020. In February 2021 legislation was introduced to fine those who violate social distancing rules. Thus, with the other parameters unchanged, suppose $c_{p}^{C}=0.85$ and $c_{p}^{M}=0.85$. Figures 13 (a) and (b) show the eventual outcome of a high-penalty regime in Japan if the Japanese government begins to gradually increase penalties in the future. It is not hard to see that the excessively high punishment mechanism will not lead the Japanese government to implement strict restrictions. It went from probability 1 to probability 0.9 . Given the high penalty regime, the Japanese government is likely to impose strict restrictions, but not necessarily. Thus, it implies that in Japan, a high subsidy mechanism is more appropriate than a punishment mechanism.

India did not experience a national lockdown in the second wave of the outbreak. Disease surveillance through IDSP in India faces a chronic shortage of funding and manpower, resulting in a weak national data collection system. There is a distinct lack of epidemiologists in senior decision-making positions on COVID-19 related committees. Some warnings about a surge in cases in March 2021, a shortage of life-saving equipment and a second wave of the epidemic, were scaled back and ignored. Many of the problems with India's failure to respond to the second wave of the epidemic are general and chronic problems with India's public health system.

Based on the actual active prevention situation in India, we assume the basic parameters value: $R_{M}=0.55 ; R_{c}^{a}=0.25$; $R_{C}^{r}=0.65 ; u_{b}=0.25 ; c_{0}=0.35 ; c_{C}^{G}=0.25 ; c_{M}^{G}=0.25 ; u_{h}=0.35 ; u_{o}=0.35 ; W=0.25 ; c_{m}^{C}=0.35 ; W_{0}=0.2 ;$ $c_{p}^{C}=0.25 ; S_{G}^{M}=0.65 ; S_{G}^{C}=0.35 ; c_{p}^{M}=0.25 ; S^{M}=0$. During COVID-19, the Indian government adopted a policy combination of high subsidies and low penalties. According to the actual situation in India, we simulated the final strategic choices of the Indian government, businesses, and consumers under different subsidy policies. Figure 13 (a) shows possible evolutionary stable strategies for India when $S_{G}^{M}<0.75$ and $S_{G}^{C}<0.75$; Figure 13 (b) shows the Indian ultimate evolutionary stable strategy when $S_{G}^{M}<0.75$ and $S_{G}^{C}<0.75$, based on the initial actual attitude of the Indian government and citizens to fight the epidemic. With the other parameters unchanged, suppose $S_{G}^{M}=0.85$ and $S_{G}^{C}=0.85$. Figure 14 shows possible evolutionary stable strategies for India when $S_{G}^{M}=0.85$ and $S_{G}^{C}=0.85$. 


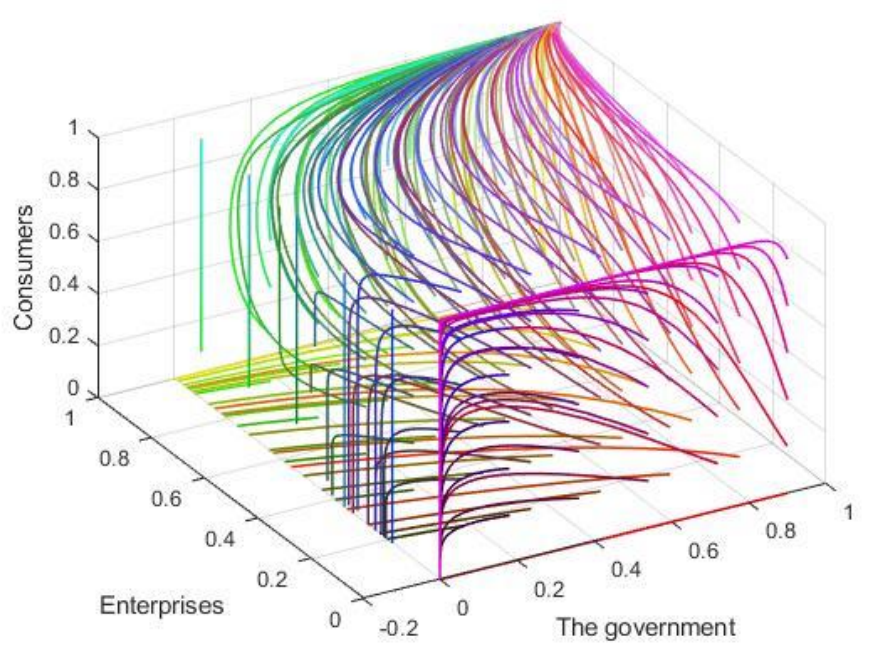

Figure 14 (a). Possible evolutionary stable strategies for India when $S_{G}^{M}<0.75$ and $S_{G}^{C}<0.75$

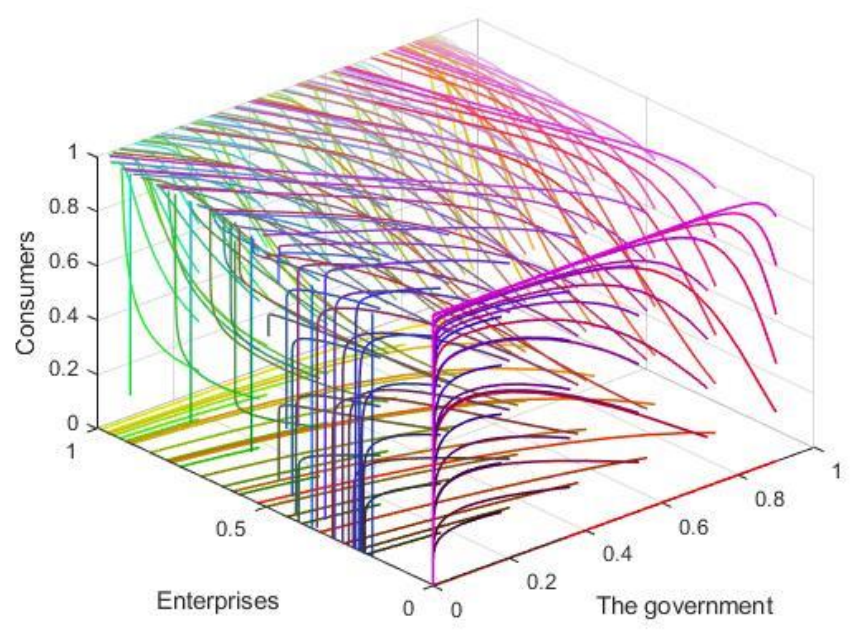

Figure 15 (a). Possible evolutionary stable strategies for India when $S_{G}^{M} \geq 0.75$ and $S_{G}^{C} \geq 0.75$

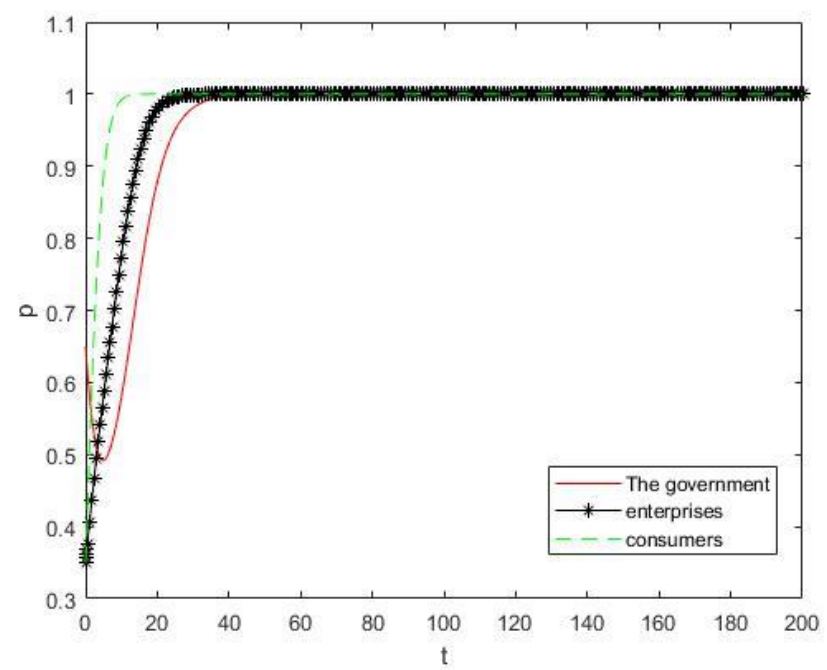

Figure 14 (b) India's ultimate evolutionary stable strategy when $S_{G}^{M}<0.75$ and $S_{G}^{C}<0.75$

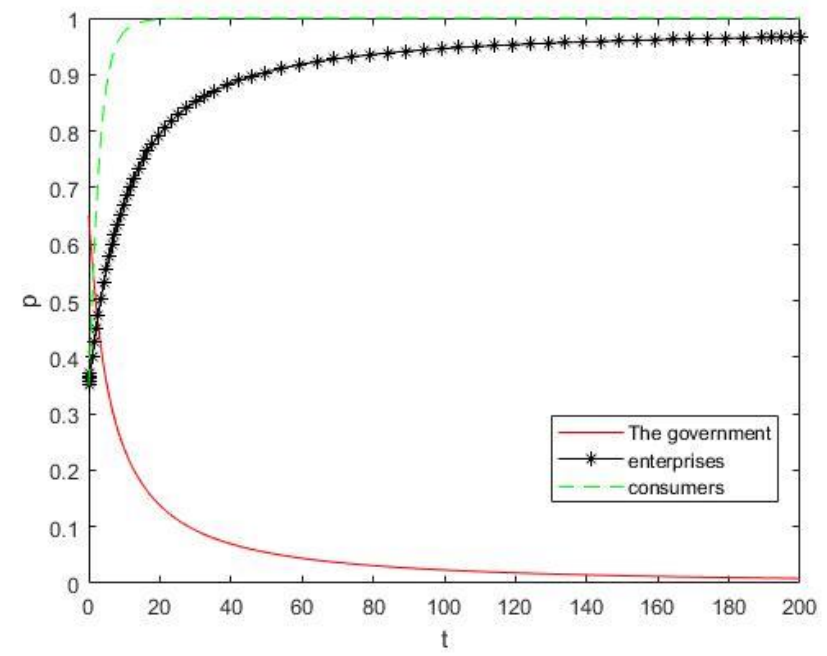

Figure 15 (b) India's ultimate evolutionary stable strategy when $S_{G}^{M} \geq 0.75$ and $S_{G}^{C} \geq 0.75$

From Figure 14 and 15, it is not difficult to see that when the subsidy from the Indian government falls below a threshold, the Indian society can finally form a unified front against the pandemic. When the subsidy from the Government of India is above this threshold, the ultimate choice of the Indian government is divergent, that is, the Indian Government will not choose to fight the pandemic. This explains why, when the second wave arrived, the Indian government switched from an active response to a passive response.

The comparison of Japan and India highlights the role of subsidies and penalties in participants' decision-making. To sum up, we demonstrate through numerical simulation that punishment and subsidy mechanisms do have a significant impact on governments, businesses, and consumers' decision-making during COVID-19. Through numerical simulation, we also proved that the application of evolutionary game theory in decision management aligns with reality during COVID-19. 


\section{Conclusion}

We have answered two research questions for this paper. Q1: What are the long-term strategy profiles for government, businesses, and consumers during COVID-19? Through the solution of the evolutionary game model and numerical analysis, we find that there are four possible situations during COVID-19 in a country: 1. Consumers fight the pandemic alone, while governments and businesses do not support via active prevention. 2. Consumers and businesses fight the epidemic together, and the government does not support fighting the pandemic. 3. As the government fights the epidemic alone, consumers and businesses choose to ignore the seriousness of COVID-19. 4. The government, businesses and consumers form a united front to fight the pandemic.

Q2: Whether penalty and subsidy mechanisms can influence the strategy profile made by governments, businesses, and consumers during COVID-19? There may be a variety of reasons for different ESS, such as citizens' trust in the government, businesses profits in COVID-19, and the cost of government control of the pandemic. This paper focuses on analyzing the influence of subsidy and punishment mechanism on the final strategy profile of government, businesses, and consumers. We find that neither too high (or too low) a subsidy nor a penalty leads to evolutionary stable strategies. Evolutionary stable strategies occur only when subsidies and penalties are set within a reasonable range. In particular, the best strategy profile is the government, businesses, and consumers to work together to fight the pandemic. Our research finds that this strategy profile requires the government to formulate a lower subsidy and a higher penalty mechanism.

Our numerical analysis results support this conclusion. Through numerical analysis, we simulate the choice of active prevention strategies in Japan and India. We explained why Japan fought the pandemic successfully, and why India's fight against the second wave failed. The Japanese government has adopted a system of high subsidies and low penalties that greatly incentivizes Japanese citizens and businesses. As a result, Japan has successfully coped with several waves of COVID-19 and has developed a coordinated response to the epidemic throughout its society. India adopted a high subsidy and low penalty mechanism in the second wave of COVID-19. This mechanism created a huge financial burden for the Indian Government in the second wave of COVID-19. The cost of this subsidy exceeded the desired utility of the Indian Government. Therefore, the Indian government has no incentive to continue to choose to fight the pandemic.

Although further empirical work in this area is required, our study sheds light on the strategic interaction of government, businesses and citizens and helps us understand the role of subsidies and penalties in supporting or undermining unity in fighting this and possible future pandemics. We believe that too high or too low punishment and subsidy mechanisms will not enable the government, businesses, and consumers to jointly fight the epidemic. The high cost caused by excessive subsidies will cause the government to lose the incentive to fight the epidemic, while the low subsidies will cause consumers and enterprises to reduce the incentive. Low penalties do not create enough incentives for businesses and consumers to respond positively to the pandemic.

It is also apparent that internal motivations are influential. The cultural background of a country (e.g. Asian Confucianism and Buddhism versus European liberalism) as well as trust in government will have an important impact on the decisions made by participants and ultimately the equilibrium reached. It is also worth noting that the penalty and subsidy mechanisms implemented are likely to impact citizens' level of trust in government. This provides a potential avenue for future research using game theory.

\section{Reference}


'Abe seeks opposition help for emergency virus bill as cases top 1,000', 2020, KYODO NEWS, 5 Mar, Retrieved: 6 July 2021, from https://english.kyodonews.net/news/2020/03/8e3a09d112dd-breaking-news-japans-coronavirus-cases-reach1000.html.

'Coronavirus: Rs 3,000 relief for construction workers, says Punjab CM Amarinder Singh', 2020, The Times of India, 22 March, Retrieved: 18 July 2021, from https://timesofindia.indiatimes.com/city/chandigarh/coronavirus-rs-3000-relief-forconstruction-workers-says-punjab-cm-amarinder-singh/articleshow/74754595.cms

'COVID-19 Assistance Programs', 2021, KPMG, 1 July. Retrieved 7 July 2021, from https://assets.kpmg/content/dam/kpmg/au/pdf/2020/covid-19-government-assistance-programs.pdf.

'Fifth Meeting of the Novel Coronavirus Response Headquarters', 2020, Prime Minister of Japan and His Cabinet, 5 February, Retrieved: 6 July 2021, from http://japan.kantei.go.jp/98_abe/actions/202002/_00006.html.

'How to reduce physical contact with others by 80\%: Japan medical experts', 2020, Minichi Japan, 10 April, Retrieved: 6 July 2021, from https://mainichi.jp/english/articles/20200410/p2a/00m/0na/018000c.

'Second Meeting of the Novel Coronavirus Response Headquarters', 2020, Prime Minister of Japan and His Cabinet, 31 January, Retrieved: 6 July 2021, from http://japan.kantei.go.jp/98_abe/actions/202001/_00037.html.

Anupam, K. B., Mehedi, M., et al. (2020). "Controlling the Outbreak of COVID-19: A Noncooperative Game Perspective", IEEEAccess, Vol. 8, 215570-215579.

Chen, S. X., Ben, C. P. L., et al. (2020). Effects of Containment and Closure Policies on Controlling the COVID-19 Pandemic in East Asia. Asian Journal of Social Psychology, Vol. 24, 42-47.

Hart, S., \& Mas-Colell, A. (1997). Cooperation: Game-Theoretic Approaches. Springer, Berlin.

Hindustan, T., and New, D. 2020, 'How conference hall at health ministry emerged as coronavirus-control war-room', Hindustan Times, 05 March, Retrieved: 18 July 2021, from https://www.hindustantimes.com/india-news/coronavirus-warroom-india-in-mission-mode/story-NHYzzcrmFUDg191PUSbjVM.html

Hindustan, T., and New, D. 2020, 'Kerala government announces Rs 20,000 crore package to tackle coronavirus outbreak', Hindustan Times, 20 March, Retrieved: 18 July 2021, from https://www.hindustantimes.com/indianews/kerala-government-announces-rs-20-000-crore-package-to-tackle-coronavirus-outbreak/storyKzGvehTH4HXjhnkTBLU49M.html

Iyer, P. V. 2020, 'Math behind Rs 20-lakh crore economic package: It is 10\% of GDP but about half is already factored in', The Indian Express , 15 May, Retrieved: 18 July 2021, from https://indianexpress.com/article/explained/the-math-its10-of-gdp-but-less-than-5-cash-outgo-pm-modi-relief-packages-6407302/

Kaori, M., Isamu, Y., et al. (2020). "Japanese citizens' behavioral changes and preparedness against COVID-19: An online survey during the early phase of the pandemic", PLOS ONE, Vol. 15(6), 1-18.

Kim, S., and Liu, B. F. (2012). “Are All Crises Opportunities? A Comparison of How Corporate and Government Organizations Responded to the 2009 Flu Pandemic", Journal of Public Relations Research, Vol. 24, 69-85.

Kim, S., and Liu, B. F. (2012). Are All Crises Opportunities? A Comparison of How Corporate and Government Organizations Responded to the 2009 Flu Pandemic. Journal of Public Relations Research, Vol. 24, 69-85.

Mitsuru, O. 2021, 'Japan's COVID penalty law: five things to know', Nikkei Asia, 3 February, Retrieved: 7 July 2021, from https://asia.nikkei.com/Spotlight/Coronavirus/Japan-s-COVID-penalty-law-five-things-to-know.

Murat, O., and Burhaneddin, L. (2021). "Effects of the quarantine on the individuals' risk of Covid-19 infection: Game theoretical approach", Alexandria Engineering Journal, Vol. 60, 4157-4165. 
New, D. 2020, 'Coronavirus: FM Sitharaman announces package worth Rs 1,70,000 crore for poor, daily wagers', 26 March, India Today, Retrieved: 18 July 2021, from https://www.indiatoday.in/business/story/finance-minister-nirmalasitharaman-live-updates-economic-relief-package-india-coronavirus-1659912-2020-03-26

Nikhil, R. 2021, 'Why India's second wave has been deadlier, explained in five charts', Live Mint, 15 May, Retrieved: 18 July 2021, from https://www.livemint.com/news/india/why-india-s-second-wave-has-been-deadlier-in-five-charts$11620799582212 . h t m l$

Saitō, K. 2020, ‘Coronavirus Basic Policy Impacts Japan's Health, Education Systems’, Nippon, 2 Mar, Retrieved: 6 July 2021, from https://www.nippon.com/en/news/100269/coronavirus-basic-policy-impacts-japan\%e2\%80\%99s-healtheducation-systems.html?cx_recs_click=true.

Sharan, P. 2020, '₹1,610-crore relief for those hardest-hit by lockdown in Karnataka', Live Mint, 06 May, Retrieved: 18 July 2021, from https://www.livemint.com/news/india/-1-610-crore-relief-for-those-hardest-hit-by-lockdown-inkarnataka-11588784599700.html

Silva, J. A. T., \& Tsigaris, P. (2020). Policy Determinants of COVID-19 Pandemic-Induced Fatality Rates Across Nations. Public Health, Vol. 187, 140-142.

Silva, J. A. T., and Tsigaris, P. (2020). "Policy Determinants of COVID-19 Pandemic-Induced Fatality Rates Across Nations", Public Health, Vol. 187, 140-142.

Surbhi, B., and Sneha, A. 2020, 'Covid-19 shows why we need a healthcare reboot for India', Live Mint, 30 March, Retrieved: 18 July 2021, from https://www.livemint.com/politics/policy/will-covid-19-prompt-health-reboot11585497828527.html

Vallejo, B. M., \& Ong, R. A. C. (2020). Policy Responses and Government Science Advice for the COVID 19 Pandemic in the Philippines: January to April 2020. Progress in Disaster Science, 1-21.

Vallejo, B. M., and Ong, R. A. C. (2020). "Policy Responses and Government Science Advice for the COVID 19 Pandemic in the Philippines: January to April 2020", Progress in Disaster Science, 1-21.

Vatsala, G., and Bureau, ET. 2020, 'Yogi Adityanath announces relief measures for UP's daily wage earners', The Economic Times, 21 March, Retrieved: 18 July 2021, from https://economictimes.indiatimes.com/news/politics-andnation/yogi-adityanath-announces-relief-measures-for-ups-daily-wage-earners/articleshow/74744711.cms?from=mdr

Vidya, K. 2020, 'Epidemiologists say India's center for disease control withheld COVID-19 data since pandemic began', 12 May, Retrieved: 18 July 2021, from https://caravanmagazine.in/health/epidemiologists-say-india-centre-diseasecontrol-withheld-covid-19-data-since-pandemic-began

Yael, P., and Uri, Y. (2020). "Reducing risk of infection - The COVID-19 queueing game", Safety Science, Vol. 132, 113.

Zhi, X., Yukun, C., and Shuangliang, Y. (2021). "Tripartite Evolutionary Game Model for Public Health Emergencies", Discrete Dynamics in Nature and Society, Vol. 2021, 1-14.

Lee, J. J., Kang, K., et al., (2020). “Associations Between COVID-19 Misinformation Exposure and Belief With COVID19 Knowledge and Preventive Behaviors: Cross-Sectional Online Study”, Journal of Medical Internet Research, Vol. 22(11), e22205.

Kouzy, R., Joseph, A. J., et al. (2020). "Coronavirus Goes Viral: Quantifying the COVID-19 Misinformation Epidemic on Twitter", Cureus, Vol. 12(3), e7255. 


\section{Supplementary Files}

This is a list of supplementary files associated with this preprint. Click to download.

- Supplementaryfile.docx 